\title{
Fabaceae endémicas del Perú
}

\section{Severo Baldeón ${ }^{1}$, Mercedes Flores ${ }^{2}$ y José Roque ${ }^{1}$}

${ }^{1}$ Museo de Historia Natural, Av. Arenales 1256, Aptdo. 14-0434, Lima 14, Perú. severobaldeon2@hotmail.com peperoque@yahoo.com ${ }^{2}$ Herbario del Departamento de Biología (MOL), Facultad de Ciencias, Universidad Nacional Agraria La Molina. Aptdo. 456, Lima, Perú.

mflores@lamolina.edu.pe

\section{Resumen}

La familia Fabaceae es reconocida en el Perú por presentar alrededor de 145 géneros y 1000 especies (Brako \& Zarucchi, 1993; Ulloa Ulloa et al., 2004), mayormente árboles y arbustos. En este trabajo reconocemos 234 especies y 40 variedades como endémicas en 47 géneros. Un género, Weberbauerella, es endémico del Perú. Sin lugar a dudas, el género con mayor número de especies endémicas es Lupinus, siendo al mismo tiempo el que mayor necesidad tiene de estudios taxonómicos detallados y mayor recolección. Las Fabaceae endémicas ocupan la mayoría de regiones, principalmente la Mesoandina, Puna Húmeda y Seca y Bosques Muy Húmedos Montanos, entre los 1100 y 4800 m de altitud. Se aplicaron las categorías y criterios de la UICN a 203 taxones. Diecisiete taxones endémicos se encuentran representados dentro del Sistema Nacional de Áreas Naturales Protegidas por el Estado.

Palabras claves: Fabaceae, Weberbauerella, Perú, endemismo, plantas endémicas.

\section{Abstract}

The Fabaceae are represented in Peru by 145 genera and 1000 species (Brako \& Zarucchi, 1993; Ulloa Ulloa et al., 2004), mainly trees and shrubs. Here we recognize as Peruvian endemics 234 species and 40 varieties in 47 genera. One genus, Weberbauerella, is endemic to Peru. Undoubtedly, Lupinus is the genus with the largest number of endemic species in the family, and at the same time, the genus that most needs detailed taxonomic studies and more collection. Endemic Fabaceae are found in almost all regions, mainly Mesoandean, Humid and Dry Puna, and Very Humid Montane Forests, between 1100 and 4800 m elevation. We applied IUCN categories and criteria to 203 taxa. Seventeen endemic taxa have been recorded within Peru's protected areas system.

Keywords: Fabaceae, Weberbauerella, Peru, endemism, endemic plants.

\section{Acacia klugii Standl. ex J.F. Macbr.}

Publicación: Field Mus. Nat. Hist., Bot. Ser. 13(3/1): 78. 1943.

Colección tipo: G. Klug 4272

Hembarios: MO, U.

Nombre común: D esconocido.

Registro departamental: LO, PA, SM.

Regiones Ecológicas: BMHP; 400-800 m.

SINAN PE: Sin registro.

Herbarios peruanos: USM?

Observaciones: Estetaxón fue considerado por Brako \& Zarucchi (1993) como un endemismo; sin embargo, no ha sido posible evaluarlo, ni asignarle una categoría.

\section{Adesmia augustiJ.F. Macbr.}

Publicación: Publ. Field Columbian Mus., Bot. Ser. 8(2): 100. 1930.

Colección tipo: A. Weberbauer 7389

Herbarios: F, GH.

Nombre común: D esconocido.

Registro departamental: AR, TA.

Regiones Ecológicas: MA; $2900 \mathrm{~m}$.

SINAN PE: Sin registro.

Hembarios peruanos: Ninguno.
Observaciones: Este taxón fue considerado por Brako \& Zarucchi (1993) como un endemismo; sin embargo, no ha sido posible evaluarlo, ni asignarle una categoría.

\section{Adesmia hispidula (Lag.) DC.}

Publicación: Ann. Sci. Nat. (Paris) 4: 95. 1825.

Colección tipo: J. D ombey s.n.

Herbarios: $P$.

Nombre común: D esconocido.

Registro departamental: AN, CU, HU, HV, LI.

Regiones Ecológicas: MA; 2880-3200 m.

SINANPE: Sin registro.

Herbarios peruanos: Ninguno.

Observaciones: Este taxón fue considerado por Brako \& Zarucchi (1993) como un endemismo; sin embargo, no ha sido posible evaluarlo, ni asignarle una categoría.

\section{Aeschynomene weberbauen Ulbr.}

\section{NT}

Publicación: Bot. Jahrb. Syst. 37(5): 554. 1906.

Colección tipo: A. Weberbauer 4274

Herbarios: B, US; MOL!.

Nombre común: D esconocido.

Registro departamental: AM, CA, LL.

Regiones Ecológicas: MA, BS; $1100-2800 \mathrm{~m}$.

SINANPE: Sin registro.

Herbarios peruanos: CPUN (8), HAO (2), HUT (3), MOL (isotipo).

Nota del Editor: En la versión on line de este artículo han sido omitidos los mapas del Perú que ilustraban el Registro departamental. Para ubicar las abreviaturas de los departamentos vea al final del artículo. 
Observaciones: Planta leñosa conocida de varias localidades a lo largo de la parte semixérica de la cuenca del Marañón. Esta especie es apetecible por el ganado.

\section{Affonsea gereauana Pipoly \& R. Vásquez}

\section{DD}

Publicación: Novon 4(2): 169-171, f. 1. 1994.

Colección tipo: R. Vásquez et al. 14326

Herbarios: F, G, K, MO, NY, P, US;

AMAZ, USM.

Nombre común: D esconocido.

Registro departamental: LO.

Regiones Ecológicas: BHA; 100-200 m.

SINANPE: RNAM

Herbarios peruanos: AMAZ (isotipo

citado), USM (isotipo citado).

Observaciones: Este árbol se conoce de la colección original, una planta recolectada en 1990. Esta especie probablemente sea una especialista de hábitat. Ha sido recolectada en una parcela de inventario en la Reserva Nacional Allpahuayo-Mishana.

\section{Albizia multiflora (Kunth) Barneby \& J.W. Grimes var. sagasteguii Barneby \& Grimes}

Publicación: Mem. New York Bot. Gard. 74(1): 237. 1997.

Colección tipo: A. Sagástegui A. 15419

Herbarios: F, NY; HUT?

Nombre común: D esconocido.

Registro departamental: CA.

Regiones Ecológicas: MA; $1200 \mathrm{~m}$.

SINANPE: Sin registro.

Herbarios peruanos: HAO (1).

Observaciones: Este arbusto pequeño se conoce solamente de una localidad en la vertiente del Pacifico, al sur del D epartamento de Cajamarca. No ha sido posible evaluarlo, ni asignarle una categoría.

\section{Astragalus bryogenes Barneby}

\section{DD}

Publicación: Brittonia 36(2): 171-173,

f. 2.1984.

Colección tipo: L. Landrum 4632

Herbarios: NY.

Nombre común: D esconocido.

Registro departamental: JU.

Regiones Ecológicas: PSH; 4000-4500 m.

SINANPE: RNJ

Hembarios peruanos: Ninguno.

Observaciones: Hierba terrestre,al parecer conocida sólo de la localidad original, en la Reserva Nacional de Junín. A parentemente, no ha vuelto a ser recolectada desde 1982

\section{Astragalus cracca DC.}

\section{DD}

Publicación: Astragalogia 101, t. 9. 1802.

Colección tipo: J. D ombey s.n.

Herbarios: $G$.

Nombre común: D esconocido.

Registro departamental: AN, LI, LL.

Regiones Ecológicas: MA; 2700-3300 m.

SINANPE: Sin registro.

Hemarios peruanos: Ninguno.
Observaciones: Hierba terrestre conocida del centro del país de las cuencas del Pativilca y Chillón. Las colecciones más recientes provienen, al parecer, de los años 1940.

\section{Astragalus dillinghamii J.F. Macbr.}

\section{DD}

Publicación: Publ. Field Columbian Mus., Bot. Ser. 8(2): 98-99. 1930.

Colección tipo: J.F. Macbride \& W. Featherstone 1052

Hemarios: $F$.

Nombre común: D esconocido.

Registro departamental: JU.

Regiones Ecológicas: PSH; 3900-4000 $\mathrm{m}$.

SINAN PE: Sin registro.

Herbarios peruanos: Ninguno.

Observaciones: Hierba conocida, aparentemente, de la cuenca alta del Mantaro y que no ha sido recolectada desde 1922.

\section{Astragalus dombeyi Fisch.}

\section{NE}

Publicación: Bull. Soc. Imp. Naturalistes Moscou 26(2): 483. 1853.

Colección tipo: J. D ombey s.n.

Herbarios: $\mathrm{P}$.

Nombre común: D esconocido.

Registro departamental: JU, LI.

Regiones Ecológicas: MA; 3000 m.

SINAN PE: Sin registro.

Henbarios peruanos: Ninguno.

Observaciones: Esta especie es un arbusto bajo con vínculos muy estrechos a A stragalus garbanaillo. El género necesita una revisión moderna y por tanto se deja sin evaluar.

\section{Astragalus neobarnebyanus Gómez-Sosa}

\section{CR, Blab(iii)}

Publicación: Brittonia 38(4): 427-429, f. 1.1986.

Colección tipo: M.O. Dillon \& D. Dillon 3813

Hembarios: F, NY, SI.

Nombre común: D esconocido.

Registro departamental: AR.

Regiones Ecológicas: D ST; $230-600 \mathrm{~m}$.

SINANPE: Sin registro.

Herbarios peruanos: Ninguno.

Observaciones: Esta hierba postrada se conoce solamente de una localidad en el sur del país. Esta es una especie claramente diferente que las otras consideradas restringidas al país y de límites poco claros con A stragalus garbancillo. No ha vuelto a ser recolectada desde 1983. Con sus flores de estandarte blanco a rosado y quilla púrpura destaca en los arenales de lomas. Los ambientes costeros en la localidad original no reciben protección por parte del Estado. 
12. Astragalus pickeringii A. Gray

LC

Publicación: U.S. Expl. Exped., Phan. 1: 415. 1854.

Colección tipo: C. Wilkes, Exped. Expl. US. 864

Henbarios: G H, K, P, US.

Nombre común: D esconocido.

Registro departamental: AN, HU, JU, LI, PA.

Regiones Ecológicas: PSH, AA; 3750$4370 \mathrm{~m}$.

SINAN PE: Sin registro.

Herbarios peruanos: USM?.

Observaciones: Esta hierba decumbente se conoce solamente del centro del país. Ha sido recolectada en más de diez localidades en pajonales fuertemente intervenidos y en áreas expuestas. Por su continua recolecta y preferencia de hábitat se la considera en Preocupación Menor.

\section{Astragalus nomasanus Ulbr.}

\section{DD}

Publicación: Bot. Jahrb. Syst. 37: 421. 1906.

Colección tipo: A. Weberbauer 3209

Henbarios: F; MOL.

Nombre común: D esconocido.

Registro departamental: AN, LL, PU.

Regiones Ecológicas: MDE, MA, PSH; 2200-3500 m.

SINANPE: Sin registro.

Herbarios penuanos: MOL (isotipo), USM (1).

Observaciones: Subarbusto, aparentemente conocido de localidades aisladas y dispersas en los Andes. Habita matorrales y pajonales intervenidos, como en la cuenca del Nepeña. Poco se sabe del estado de sus poblaciones.

\section{Astragalus sagasteguii Gómez-Sosa}

\section{EN, Bla}

Publicación: Novon 15(4): 542-544, f. 1. 2005.

Colección tipo: A. Sagástegui A. 11181

Herbarios: F, MO, NY, SI.

Nombre común: D esconocido.

Registro departamental: CA.

Regiones Ecológicas: PAR; $3800 \mathrm{~m}$.

SINANPE: Sin registro.

Herbarios peruanos: Ninguno.

Observaciones: Hierba postrada y pulvinada conocida de ambientes de jalca, en la cuenca alta del Chusgón, un tributario del Marañón. Poco se sabe del tamaño de sus poblaciones, aunque la jalca que habita está sujeta a incendios intencionales y pastoreo intensivo. Aparentemente, el ejemplar original del Herbario Truxillense no se encuentra en esa institución (E. Rodriguez, com. pers., 2006).

\section{Bauhinia accrescens Killip \& J.F. Macbr.}

Publicación: Field Mus. Nat. Hist., Bot. Ser. 13(3/ 1): 209. 1943.

Colección tipo: G. Klug 528

Hemanios: US.

Nombre común: D esconocido.

Registro departamental: LO.

Regiones Ecológicas: BHA; $100 \mathrm{~m}$.

SINAN PE: Sin registro.

Herbarios peruanos: Ninguno.

Observaciones: Este taxón fue considerado por Brako \& Zarucchi (1993) como un endemismo; sin embargo, no ha sido posible evaluarlo, ni asignarle una categoría.

\section{Bauhinia guentheni $\mathrm{Harms}$}

Publicación: Notizbl. Bot. Gart. BerlinDahlem 9:969. 1926.

Colección tipo: G. Tessmann 4375

Hemarios: B.

Nombre común: D esconocido.

Registro departamental: AM, LO.

Regiones Ecológicas: BHA; altitud desconocida.

SINANPE: Sin registro.

Herbarios peruanos: Ninguno.

Observaciones: Este taxón fue considerado por Brako \& Zarucchi (1993) como un endemismo; sin embargo, no ha sido posible evaluarlo, ni asignarle una categoría.

\section{Bauhinia porphyrotricha H arms var. killipiana (Standl.) J.F. Macbr.}

Publicación: Field Mus. Nat. Hist., Bot. Ser. 13(3/ 1): 215. 1943.

Colección tipo: G. Klug 4289

Herbarios: $F$.

Nombre común: D esconocido.

Registro departamental: SM.

Regiones Ecológicas: $\mathrm{BMHP}, \mathrm{BHA}$; 400-800 m.

SINAN PE: Sin registro.

Herbarios peruanos: Ninguno.

Observaciones: Estetaxón fue considerado por Brako \& Zarucchi (1993) como un endemismo; sin embargo, no ha sido posible evaluarlo, ni asignarle una categoría.

\section{Bauhinia porphyrotricha Harms var. smithiana Killip \& J.F. Macbr.}

Publicación: Field Mus. Nat. Hist., Bot. Ser. 13(3/ 1): 215. 1943.

Colección tipo: E.P. Killip \& A.C. Smith 26296

Hembarios: F, US.

Nombre común: D esconocido.

Registro departamental: JU, PA.

Regiones Ecológicas: BHA; $400 \mathrm{~m}$.

SINAN PE: Sin registro.

Herbarios peruanos: Ninguno. 
Observaciones: Este taxón fue considerado por Brako \& Zarucchi (1993) como un endemismo; sin embargo, no ha sido posible evaluarlo, ni asignarle una categoría.

\section{Brownea peruviana J.F. Macbr.}

$$
\text { CR, Blab(iii) }
$$

Publicación: Field Mus. Nat. Hist., Bot. Ser. 13(3/ 1): 134- 135. 1943.

Colección tipo: G. Klug 4391

Herbarios: F, MO, US.

Nombre común: D esconocido.

Registro departamental: SM.

Regiones Ecológicas: $\mathrm{BMHP}, \mathrm{BHA}$; 400- $800 \mathrm{~m}$.

SINANPE: Sin registro.

Hembarios peruanos: Ninguno.

Observaciones: Esta especie pertenece al género Browneopsis y como tal fue listada en Brako \& Zarucchi (1993), pero la combinación permanece inédita de acuerdo a las reglas nomenclaturales. Se conoce solamente de la cuenca media del Huallaga. No ha vuelto a ser recolectada desde 1936.

\section{Caesalpinia chicamana Killip \& J.F. Macbr.}

Publicación: Field Mus. Nat. Hist., Bot. Ser. 13(3/ 1): 191- 192. 1943.

Colección tipo: B.B. Smyth 74

Herbarios: US.

Nombre común: D esconocido.

Registro departamental: LL.

Regiones Ecológicas: D ST; altitud desconocida.

SINAN PE: Sin registro.

Herbarios peruanos: Ninguno.

Observaciones: Esta es una especie recolectada en el valle del Chicama en La Libertad, pero registrada erróneamente para Lima. No ha sido posible evaluarla, ni asignarle una categoría.

\section{Caesalpinia paipai Ruiz \& Pav. var. pubensJ.F. Macbr.}

\section{DD}

Publicación: Field Mus. Nat. Hist., Bot Ser. 13(3/ 1): 193. 1943.

Colección tipo: A. Weberbauer 5994

Herbarios: $F$.

Nombre común: D esconocido.

Registro departamental: PI.

Regiones Ecológicas: D CT; 170- 200 m.

SINAN PE: Sin registro.

Herbarios peruanos: Ninguno.

Observaciones: Arbusto no espinoso, conocido solamente de una colección en la cuenca del Piura. Al. parecer, no ha vuelto a ser recolectado desde 1912.

\section{Calliandra chotanoana H arms}

Publicación: Repert. Spec. Nov. Regni Veg. 17: 442. 1921.

Colección tipo: A. Weberbauer 7123

Herbarios: B, F, US.

Nombre común: D esconocido.

Registro departamental: AM, CA.

Regiones Ecológicas: Sin datos; 1000$1100 \mathrm{~m}$.

SINAN PE: Sin registro.

Herbarios peruanos: Ninguno.

Observaciones: Este taxón fue considerado por Brako \& Zarucchi (1993) como un endemismo; sin embargo, no ha sido posible evaluarlo, ni asignarle una categoría.

\section{Calliandra decrescens Killip \& J.F. Macbr.}

\section{DD}

Publicación: Field Mus. Nat. Hist., Bot. Ser. 13(3/ 1): 71. 1943.

Colección tipo: G. Klug 152

Herbarios: NY, US.

Nombre común: D esconocido.

Registro departamental: LO.

Regiones Ecológicas: BHA; $100 \mathrm{~m}$.

SINAN PE: Sin registro.

Herbarios peruanos: Ninguno.

Observaciones: Árbol conocido solamente de los alrededores de Iquitos. Al parecer, no ha vuelto a ser recolectada desde 1929.

\section{Calliandra expansa Benth.}

$$
\text { EN, B1a }
$$

Publicación: Trans. Linn. Soc. London 30(3): 549. 1875.

Colección tipo: H. Ruiz \& J. Pavón s.n.

Herbarios: MA.

Nombre común: D esconocido.

Registro departamental: AN, HU, LL.

Regiones Ecológicas: MA; $2200 \mathrm{~m}$.

SINAN PE: Sin registro.

Herbarios peruanos: Ninguno.

Observaciones: Arbusto conocido de varias localidades mesoandinas, creciendo en ambientes semixéricos. El ejemplar tipo fue recolectado en el siglo XVIII. Otras poblaciones conocidas están ubicadas en las cuencas del Santa y del Marañón.

\section{Calliandra prostrata Benth.}

Publicación: Trans. Linn. Soc. London 30(3): 554. 1875.

Colección tipo: J. Maclean s.n.

Herbarios:

Nombre común: D esconocido.

Registro departamental: AN, AR, CA, LI.

Regiones Ecológicas: Sin datos; altitud desconocida.

SINAN PE: Sin registro.

Herbarios peruanos: Ninguno.

Observaciones: Este taxón fue considerado por Brako \& Zarucchi (1993) como un endemismo; sin embargo, no ha sido posible evaluarlo, ni asignarle una categoría. 


\section{Calliandra rotundifolia Killip \& J.F. Macbr.}

Publicación: Field Mus. Nat. Hist., Bot. Ser. 13(3/ 1): 73. 1943.

Colección tipo: G. Klug 421

Herbarios: US.

Nombre común: D esconocido.

Registro departamental: LO.

Regiones Ecológicas: BHA; $100 \mathrm{~m}$.

SINAN PE: Sin registro.

Herbarios peruanos: Ninguno.

Observaciones: Este taxón fue considerado por Brako \& Zarucchi (1993) como un endemismo; sin embargo, no ha sido posible evaluarlo, ni asignarle una categoría.

\section{Calliandra tumbeziana J.F. Macbr.}

Publicación: Publ. Field Columbian Mus., Bot. Ser. 8(2): 89-90. 1930.

Colección tipo: A. Weberbauer 7677

Herbarios: $F$.

Nombre común: D esconocido.

Registro departamental: TU.

Regiones Ecológicas: MDE; altitud desconocida.

SINANPE: Sin registro.

Herbarios peruanos: Ninguno.

Observaciones: Este taxón fue considerado por Brako \& Zarucchi (1993) como un endemismo; sin embargo, no ha sido posible evaluarlo, ni asignarle una categoría.

\section{Canavalia wurdackii Aymard \& Cuello}

\section{DD}

Publicación: BioLlania 8: 88, f. 2-3. 1991.

Colección tipo: J.J. Wurdack 1107

Herbarios: NY, US.

Nombre común: D esconocido.

Registro departamental: AM.

Regiones Ecológicas: BMHM; 1600$1900 \mathrm{~m}$.

SINANPE: Sin registro.

Herbarios peruanos: Ninguno.

Observaciones: Liana conocida de la colección tipo, una planta recolectada en 1962 de la cuenca del Utcubamba.

29. Centrosema latidens Killip \& J.F. Macbr.

Publicación: Field Mus. Nat. Hist., Bot. Ser. 13(3/ 1): 341. 1943.

Colección tipo: E.P. Killip \& A.C. Smith 27108

Herbarios: NY, US.

Nombre común: D esconocido.

Registro departamental: LO.

Regiones Ecológicas: BHA; $100 \mathrm{~m}$.

SINAN PE: Sin registro.

Herbarios peruanos: Ninguno.

Observaciones: Este taxón fue considerado por Brako \& Zarucchi (1993) como un endemismo; sin embargo, no ha sido posible evaluarlo, ni asignarle una categoría.

\section{Chaetocalyx longiloba Rudd}

Publicación: Novon 6(2): 119. 1996.

Colección tipo: C. Díaz et al. 3530

Herbarios: MO, SFV; USM!

Nombre común: D esconocido.

Registro departamental: AM.

Regiones Ecológicas: BS; 2450- 2550 m.

SINAN PE: Sin registro.

Herbarios penuanos: USM (isotipo).

Observaciones: Este taxón fue descrito posterior a Brako \& Zarucchi (1993); no ha sido posible evaluarlo, ni asignarle una categoría.

\section{Chaetocalyx platycarpa (Harms) Rudd}

DD

Publicación: Contr. U.S. Natl. Herb. 32(3): 216. 1958.

Colección tipo: A. Raimondi 6714

Herbarios: B.

Nombre común: D esconocido.

Registro departamental: CA.

Regiones Ecológicas: Sin datos; altitud desconocida.

SINANPE: Sin registro.

Herbarios peruanos: Ninguno.

Observaciones: Especie perenne conocida de varios ejemplares de la cuenca del Marañón. El ejemplar tipo fue recolectado en 1878.

\section{Chamaecrista glandulosa (L.) Greene var. balsana \\ H.S. Irwin \& Barneby}

\section{DD}

Publicación: Mem. New York Bot. Gard. 35: 794. 1982.

Colección tipo: P.C. Hutchison \& J.K. Wright 5428

Herbarios: F, K, NY, P, US; USM!

Nombre común: D esconocido.

Registro departamental: CA.

Regiones Ecológicas: BS; $800 \mathrm{~m}$.

SINANPE: Sin registro.

Herbarios peruanos: USM (isotipo).

Observaciones: Arbusto conocido aparentemente sólo dela cuenca del Marañón. El ejemplar tipo fue recolectado en 1964.

\section{Clitoria flexuosa Fantz var. flexuosa}

Publicación: 1982.

Colección tipo: R. Spruce 4527

Henbarios: K, W.

Nombre común: D esconocido.

Registro departamental: SM.

Regiones Ecológicas: BHA; 400 m.

SINANPE: Sin registro.

Herbarios peruanos: USM?.

Observaciones: Este taxón fue considerado por Brako \& Zarucchi (1993) como un endemismo; sin embargo, no ha sido posible evaluarlo, ni asignarle una categoría. 
Publicación: Sida 9(4): 301. 1982.

Colección tipo: $\mathrm{G}$. Klug 3105

Herbarios: A, BM, F, G, G H, MO.

Nombre común: D esconocido.

Registro departamental: HU, LO, SM.

Regiones Ecológicas: BHA; 220-300 m.

SINAN PE: Sin registro.

Henbarios penuanos: USM?

Observaciones: Este taxón fue considerado por Brako \& Zarucchi (1993) como un endemismo; sin embargo, no ha sido posible evaluarlo, ni asignarle una categoría.

\section{Clitonia javitensis (Kunth) Benth. var. longiloba Fantz}

Publicación: Sida 9(2): 170. 1981.

Colección tipo: G. Tessmann 3782

Herbarios: G, S.

Nombre común: D esconocido.

Registro departamental: LO.

Regiones Ecológicas: BHA; altitud desconocida.

SINANPE: Sin registro.

Herbarios peruanos: Ninguno.

Observaciones: La especie fue considerada para la flora ecuatoriana. Se precisa una reevaluación taxonómica sobre el estatus de las variedades.

\section{Clitoria juninensis Fantz}

Publicación: Sida 8(1): 95-97, f. 1. 1979. Colección tipo: E.P. Killip \& A.C. Smith 23380

Hemanios: F, NY, US.

Nombre común: D esconocido.

Registro departamental: JU.

Regiones Ecológicas: BMHP; 600- 750

m.

SINAN PE: Sin registro.

Herbarios penuanos: USM?

Observaciones: Este taxón fue considerado por Brako \& Zarucchi (1993) como un endemismo; sin embargo, no ha sido posible evaluarlo, ni asignarle una categoría.

\section{Clitoria moyobambensis Fantz}

Publicación: Sida 8(1): 99-101, f. 3. 1979.

Colección tipo: A. Mathews s.n.

Herbarios: $\mathrm{K}$.

Nombre común: D esconocido.

Registro departamental: SM.

Regiones Ecológicas: BMHP; altitud desconocida.

SINANPE: Sin registro.

Herbarios peruanos: Ninguno.

Observaciones: Estetaxón fue considerado por Brako \& Zarucchi (1993) como un endemismo; sin embargo, no ha sido posible evaluarlo, ni asignarle una categoría.

\section{Clitoria woytkowski Fantz}

Publicación: Sida 9(4): 293-294, f. 1. 1982.

Colección tipo: F. Woytkowski 7281

Herbarios: GH, MO, US.

Nombre común: D esconocido.

Registro departamental: SM.

Regiones Ecológicas: BHA; $500 \mathrm{~m}$.

SINANPE: Sin registro.

Herbarios peruanos: Ninguno.

Observaciones: Este taxón fue considerado por Brako \& Zarucchi (1993) como un endemismo; sin embargo, no ha sido posible evaluarlo, ni asignarle una categoría.

\section{Cojoba chazutensis (Standl.) L. Rico}

\section{LC}

Publicación: Kew Bull. 46(3): 507. 1991.

Colección tipo: G. Klug 4011

Hemarios: F, NY, US.

Nombre común: Aguano pashaco.

Registro departamental: AM, CA, HU, SM.

Regiones Ecológicas: BMHP, BHA; 260- $1400 \mathrm{~m}$.

SINANPE: Sin registro.

Herbarios peruanos: Ninguno.

Observaciones: Árbol conocido de varias localidades en el oriente del país, de las cuencas del Chinchipe, Mayo, Huallaga y Ucayali.

\section{Coursetia cajamarcana Lavin}

Publicación: Syst. Bot. Monogr. 21: 87. 1988.

Colección tipo: A. López M. \& A. Sagástegui A. 3154

Hemarios: US; HUT!

Nombre común: D esconocido.

Registro departamental: CA.

Regiones Ecológicas: MDE, BS; 1200 m.

SINAN PE: Sin registro.

Hemarios penuanos: HUT (isotipo).

Observaciones: Este taxón fue considerado por Brako \& Zarucchi (1993) como un endemismo; sin embargo, no ha sido posible evaluarlo, ni asignarle una categoría.

\section{Coursetia fruticosa (Cav.) J.F. Macbr.}

\section{LC}

Publicación: Publ. Field Columbian Mus., Bot. Ser. 4(4): 88. 1925.

Colección tipo: J. Pavón s.n.

Herbarios: MA.

Nombre común: Desconocido.

Registro departamental: AP, AY, CU, HU, HV, LI.

Regiones Ecológicas: MDE, MA; 1900$3000 \mathrm{~m}$.

SINANPE: Sin registro.

Herbarios peruanos: USM (4).

Observaciones: Arbusto conocido de varias localidades en el centro y sur del país, donde ocupa ambientes xéricos. 


\section{Coursetia maraniona Lavin}

Publicación: Syst. Bot. Monogr. 21: 8889, f. 85- 89. 1988.

Colección tipo: R. Ferreyra 15636

Hemarios: UC, US; USM!.

Nombre común: D esconocido.

Registro departamental: AM, CA.

Regiones Ecológicas: BS; 500-600 m.

SINAN PE: Sin registro.

Hemarios peruanos: USM (isotipo).

Observaciones: Este taxón fue considerado por Brako \& Zarucchi (1993) como un endemismo; sin embargo, no ha sido posible evaluarlo, ni asignarle una categoría.

\section{Coursetia tumbezensis J.F. Macbr.}

Publicación: Publ. Field Columbian Mus., Bot. Ser. 8(2): 97-98. 1930.

Colección tipo: A. Weberbauer 7647

Herbarios: $F$.

Nombre común: D esconocido.

Registro departamental: TU

Regiones Ecológicas: MDE; 1000 m.

SINAN PE: RNCA

Herbarios peruanos: Ninguno.

Observaciones: Arbusto conocido aparentemente sólo de la colección tipo, la que fue recolectada en 1927 de una localidad hoy en un área protegida. No ha sido posible evaluarlo, ni asignarle una categoná.

\section{Dalbergia debilis J.F. Macbr.}

\section{DD}

Publicación: Field Mus. Nat. Hist., Bot. Ser. 13(3/ 1): 286-287. 1943.

Colección tipo: G. Klug 2286

Herbarios: NY, US.

Nombre común: D esconocido.

Registro departamental: LO.

Regiones Ecológicas: BHA; $180 \mathrm{~m}$.

SINAN PE: Sin registro.

Herbarios peruanos: Ninguno.

Observaciones: Arbusto conocido aparentemente sólo de la colección tipo, una planta recolectada en un tributario del Putumayo, cerca de la frontera con Colombia.

\section{Dalbergia simpsonii Rudd}

\section{CR, B1ab(iii)}

Publicación: Phytologia 27(5): 305, f. 1. 1973.

Colección tipo: D.R. Simpson 775

Hembarios: F, NY, US.

Nombre común: D esconocido.

Registro departamental: LO.

Regiones Ecológicas: BHA; 100- 150 m.

SINANPE: Sin registro.

Herbarios peruanos: Ninguno.

Observaciones: Arbusto que se conoce solamente de una localidad, cerca dela ciudad de Iquitos. No havuelto a ser recolectada desde 1968, si bien parece ocupar ambientes con vegetación secundaria. No se conoce de alguna área protegida y dada la tasa de deforestación podría considerarse muy amenazada.
46. Dalea ayavacensis Kunth var. viridescens Barneby

Publicación: Mem. New York Bot. Gard. 27: 355, pl. 80. 1977.

Colección tipo: F. Woytkowski 8016

Herbarios:

Nombre común: D esconocido.

Registro departamental: CA.

Regiones Ecológicas: BMHM; 1850$2900 \mathrm{~m}$.

SINAN PE: Sin registro.

Herbarios peruanos: CPUN (1).

Observaciones: Hierba rara, en fragmentos de bosque. Este taxón fue considerado por Brako \& Zarucchi (1993) como un endemismo; sin embargo, no ha sido posible evaluarlo, ni asignarle una categoría.

\section{Dalea carthagenensis (Jacq.) J.F. Macbr. var.} trichocalyx (Ulbr.) Barneby

Publicación: Mem. New York Bot. Gard. 27: 523. 1977.

Colección tipo: A. Weberbauer 2994

Herbarios: NY.

Nombre común: D esconocido.

Registro departamental: AN, HV, LI, LL. Regiones Ecológicas: Sin datos; altitud desconocida.

SINANPE: Sin registro.

Herbarios peruanos: Ninguno.

Observaciones: Este taxón fue considerado por Brako \& Zarucchi (1993) como un endemismo; sin embargo, no ha sido posible evaluarlo, ni asignarle una categoría.

\section{Dalea cylindrica H ook. var. haenkeana Barneby}

Publicación: Mem. New York Bot. Gard. 27: 361-362, pl. 81. 1977.

Colección tipo: A. López M. 886

Henbarios: US.

Nombre común: Desconocido.

Registro departamental: AN, CA, HU, LL, PA.

Regiones Ecológicas: MA; 2150-3400 m.

SINAN PE: Sin registro.

Hemarios peruanos: CPUN (6).

Observaciones: Este taxón fue considerado por Brako \& Zarucchi (1993) como un endemismo; sin embargo, no ha sido posible evaluarlo, ni asignarle una categoría.

\section{Dalea cylindrica Hook. var. sulfurea (Ulbr.) Barneby}

Publicación: Mem. New York Bot. Gard. 27: 361. 1977.

Colección tipo: A. Weberbauer 3922

Herbarios: B.

Nombre común: D esconocido.

Registro departamental: CA, LL.

Regiones Ecológicas: MA; 2000- 2850 m.

SINAN PE: Sin registro.

Herbarios peruanos: CPUN (5). 
Observaciones: Planta frecuente. Este taxón fue considerado por Brako \& Zarucchi (1993) como un endemismo; sin embargo, no ha sido posible evaluarlo, ni asignarle una categoría.

\section{Dalea fieldii (J.F. Macbr.) J.F. Macbr.}

Publicación: Candollea 7(preprint): 222. 1937. Colección tipo: J.F. Macbride 3117

Herbarios: F.

Nombre común: D esconocido.

Registro departamental: PA.

Regiones Ecológicas: Sin datos; altitud desconocida.

SINAN PE: Sin registro.

Herbarios peruanos: Ninguno.

Observaciones: Este taxón fue considerado por Brako \& Zarucchi (1993) como un endemismo; sin embargo, no ha sido posible evaluarlo, ni asignarle una categoría.

\section{Dalea galbina (J.F. Macbr.) J.F. Macbr.}

Publicación: Candollea 7(preprint): 222 1937.

Colección tipo: J.F. Macbride 3500

Herbarios: $F$.

Nombre común: D esconocido.

Registro departamental: HU.

Regiones Ecológicas: MA; $2500 \mathrm{~m}$.

SINANPE: Sin registro.

Herbarios peruanos: Ninguno.

Observaciones: Arbusto conocido de la colección tipo, una planta recolectada en 1922 de los alrededores de Huánuco. No ha sido posible evaluarlo, no asignarle una categoría.

\section{Dalea glumacea Barneby}

\section{CR, B lab(iii)}

Publicación: Brittonia 40(1): 2-4, f. 1AE. 1988

Colección tipo: I. Sánchez V. 326

Herbarios: NY; CPUN!.

Nombre común: D esconocido

Registro departamental: CA.

Regiones Ecológicas: MA; $2400 \mathrm{~m}$.

SINANPE: Sin registro.

Herbarios peruanos: CPUN (holotipo).

Observaciones: Hierba conocida solamente de una localidad y no vuelta a ser observada, en el sur del valle de Cajamarca, desde 1967.

\section{Dalea isidoni Barneby}

\section{CR, Bla}

Publicación: Brittonia 40(1): 5-6, f. 1JN. 1988.

Colección tipo: I. Sánchez V. \& W. Ruiz V. 3608

Herbarios: NY; CPUN!

Nombre común: D esconocido.

Registro departamental: CA.

Regiones Ecológicas: MA; 2775- 2850

$\mathrm{m}$.

SINAN PE: Sin registro.

Herbarios peruanos: CPUN (4).
Observaciones: Subarbusto, conocido de unas pocas localidades ubicadas en un valle interandino, en una subcuenca del Crisnejas. Todos los registros conocidos provienen de áreas afectadas por reforestación con eucalipto.

\section{Dalea moquehuana J.F. Macbr.}

$$
\text { EN, Blab(iii) }
$$

Publicación: Field Mus. Nat. Hist., Bot. Ser. 13(3/ 1): 370. 1943.

Colección tipo: A. Weberbauer 7433

Henbarios: F, US; USM!.

Nombre común: D esconocido.

Registro departamental: AY, MO.

Regiones Ecológicas: MDE; 1900-2000 m.

SINAN PE: Sin registro.

Herbarios peruanos: USM (isotipo+1).

Observaciones: Hierba anual, que se conoce solamente de la vertiente occidental del sur del país. Esta especie fue descrita de una planta recolectada en 1925, en la cuenca del Moquegua. O tras poblaciones ha sido registradas en años posteriores.

\section{Dalea pennellii (J.F.Macbr) J.F. Macbr.var. pennellii}

\author{
Publicación: \\ Colección tipo: A. Weberbauer 7433 \\ Herbarios: \\ Nombre común: Desconocido. \\ Registro departamental: AR, CU. \\ Regiones Ecológicas: Sin datos; altitud \\ desconocida. \\ SINANPE: Sin registro. \\ Hembarios peruanos: Ninguno.
}

Observaciones: Este taxón fue considerado por Brako \& Zarucchi (1993) como un endemismo; sin embargo, no ha sido posible evaluarlo, ni asignarle una categoría.

\section{Dalea smithii (J.F. Macbr.) J.F. Macbr.}

LC

Publicación: Candollea 7 (preprint): 223. 1937. Colección tipo: E.P. Killip \& A.C. Smith 22180 Herbarios: F, US.

Nombre común: Desconocido.

Registro departamental: AP, AY, CU, HV. Regiones Ecológicas: MA; 2500-2950 m. SINANPE: Sin registro.

Herbarios peruanos: Ninguno.

Observaciones: Subarbusto conocido del sur del país. El ejemplar tipo fue recolectado en la cuenca del Mantaro. O tras poblaciones se conocen de las cuencas del Urubamba y del Apurímac.

\section{Dalea strobilacea Bameby}

\section{VU, Bla}

Publicación: Brittonia 33(4): 508- 510, f. 1.1981

Colección tipo: A. López M. \& A. Sagástegui A. 8222

Herbarios: NY; HUT!

Nombre común: D esconocido.

Registro departamental: CA, LL.

Regiones Ecológicas: MA; 2500-2920 m.

SINANPE: Sin registro.

Herbarios peruanos: CPUN (5), HUT (isotipo). 
Observaciones: Arbusto conocida de unas cinco localidades. El área de distribución incluye el sur del D epartamento de Cajamarca y el norte de La Libertad. Planta empleada en infusiones con fines medicinales.

\section{Dalea tridactylites Barneby}

$$
\text { EN, Blab(iii) }
$$

Publicación: Brittonia 40(1): 4- 5, f. 1FI. 1988.

Colección tipo: I. Sánchez V. 1122

Hemarios: NY; CPUN!.

Nombre común: D esconocido.

Registro departamental: CA.

Regiones Ecológicas: MDE, MA; 2500$2800 \mathrm{~m}$.

SINANPE: Sin registro.

Herbarios peruanos: CPUN (holotipo+1).

Observaciones: Subarbusto conocido de dos localidades cercanas. Los individuos de esta especie se hallan dispersos en las localidades conocidas. O cupa laderas de rocas calizas.

\section{Dalea weberbaueri Ulbr. var. sericophylla (Ulbr.) Barneby}

\section{VU}

Publicación: Mem. New York Bot. Gard. 27: 367. 1977.

Colección tipo: A. Weberbauer 4017

Herbarios: F, NY.

Nombre común: D esconocido.

Registro departamental: AN, CA, HV, JU, LL, PI.

Regiones Ecológicas: MA; 2800-3200 $\mathrm{m}$.

SINANPE: Sin registro.

Herbarios penuanos: CPUN (7), HAO (1), HUT (1).

Observaciones: Subarbusto conocido de localidades dispersas en el norte y centro del país. Este taxón ocupa ambientes modificados, como matorrales en bordes de caminos.

\section{Dalea weberbauen Ulbr. var. weberbauen}

\section{DD}

Publicación:

Colección tipo: A. Weberbauer 1739

Herbarios: B.

Nombre común: D esconocido.

Registro departamental: CA, JU.

Regiones Ecológicas: MA; 2100-3000

$\mathrm{m}$.

SINANPE: Sin registro.

Herbarios penuanos: CPUN (7), HAO (1).

Observaciones: Subarbusto descrito de una planta recolectada en 1902, de la cuenca del Palca. Otras poblaciones son, al parecer, conocido de varias localidades disyuntas, en el norte del país.

\section{Desmodium delotum J.F. Macbr.}

DD

Publicación: Publ. Field Columbian Mus., Bot. Ser. 8(2):102. 1930.

Colección tipo: J.F. Macbride 5279

Herbarios: $F$.

Nombre común: D esconocido.

Registro departamental: JU.

Regiones Ecológicas: BMHP; $650 \mathrm{~m}$.

SINANPE: Sin registro.

Herbarios peruanos: Ninguno.

Observaciones: Subarbusto que es conocido solamente de la colección tipo, proveniente de la cuenca del Tulumayo. Al parecer, no ha vuelto a ser recolectado desde 1923.

\section{Desmodium micranthum (Schindler) J.F. Macbr. var.} micranthum

\section{DD}

Publicación:

Colección tipo: A. Weberbauer s.n.

Herbarios: B.

Nombre común: Desconocido.

Registro departamental: LA.

Regiones Ecológicas: MDE; altitud desconocida.

SINANPE: Sin registro.

Herbarios peruanos: Ninguno.

Observaciones: Subarbusto aparentemente recolectado en Lambayequea inicios del siglo XX. Esta especie se conoce solamente de la colección tipo.

\section{Desmodium micranthum (Schindler) J.F. Macbr. var.} macbridei B.G. Schub.

DD

Publicación: Field Mus. Nat. Hist., Bot. Ser. 13(3/ 1): 429. 1943.

Colección tipo: A. Weberbauer 5988

Herbarios: $F$.

Nombre común: D esconocido.

Registro departamental: PI.

Regiones Ecológicas: D CT; 200- 250 m. SINANPE: Sin registro.

Herbarios peruanos: Ninguno.

Observaciones: Este taxón subarbustivo es conocido solamente de la colección tipo, una planta recolectada en los alrededores de Salitral, en el norte del país. Aunque, Schubert (1943) comentó que el ejemplar tipo carecía de datos de localidad.

\section{Desmodium vargasianum B.G. Schub. var. vargasianum}

Publicación:

Colección tipo: C. Vargas C. 769

Herbarios:

Nombre común: D esconocido.

Registro departamental: AP, AY, CU.

Regiones Ecológicas: Sin datos; altitud desconocida.

SINAN PE: Sin registro.

Herbarios peruanos: Ninguno.

Observaciones: Este taxón fue considerado por Brako \& Zarucchi (1993) como un endemismo; sin embargo, no ha sido posible evaluarlo, ni asignarle una categoría. 
65. Desmodium vargasianum B.G. Schub. var. ancuatum B.G. Schub.

\section{DD}

Publicación: Field Mus. Nat. Hist., Bot. Ser. 13(3/ 1): 436. 1943.

Colección tipo: J.F. Macbride 2859

Hembarios: $F$.

Nombre común: D esconocido.

Registro departamental: HV, LL, LI.

Regiones Ecológicas: MDE; $1000 \mathrm{~m}$.

SINANPE: Sin registro.

Herbarios peruanos: Ninguno.

Observaciones: Subarbusto conocido del centro y norte del del país, de las cuencas del Chicama, Rímac y Pisco. No se conoce el estado de sus poblaciones.

\section{Dimorphandra loretensis M.F. Silva}

\section{DD}

Publicación: Acta Amazon. 11: 54, f. sn. 1981.

Colección tipo: T. Croat 19989

Herbarios: F, NY.

Nombre común: D esconocido.

Registro departamental: LO.

Regiones Ecológicas: BHA; $100 \mathrm{~m}$.

SINANPE: Sin registro.

Hembarios peruanos: Ninguno.

Observaciones: Árbol, conocido sólo de los alrededores de Iquitos, en una subcuenca del Amazonas. Al parecer, no ha vuelto a ser recolectado desde 1972

\section{Dipteryx charapilla (J.F. Macbr.) Ducke}

Publicación: Anais Acad. Brasil. Ci. 20 49. 1948.

Colección tipo: J.M. Schunke 362

Herbarios: F, NY.

Nombre común: Charapilla.

Registro departamental: LO.

Regiones Ecológicas: BHA; altitud desconocida.

SINAN PE: Sin registro.

Hembarios peruanos: Ninguno.

Observaciones: Árbol conocido, aparentemente, sólo de la cuenca amazónica. El tipo fue recolectado en la década de 1930. No ha sido posible evaluarlo, ni asignarle una categoría.

\section{Dussia foxii Rudd}

Publicación: Contr. U.S. Natl. Herb. 32(4): 269, f. 9. 1963.

Colección tipo: W. Fox 85

Hemarios: $\mathrm{K}$.

Nombre común: D esconocido.

Registro departamental: LO.

Regiones Ecológicas: Sin datos; altitud desconocida.

SINANPE: Sin registro.

Herbarios peruanos: Ninguno.

Observaciones: Este taxón fue considerado por Brako \& Zarucchi (1993) como un endemismo; sin embargo, no ha sido posible evaluarlo, ni asignarle una categoría.
69. Galactia augusti H arms var. celendinensis Burkart

\section{DD}

Publicación: Darwiniana 16(3-4): 695. 1971.

Colección tipo: I. Sánchez V. 487

Hemarios: SI; CPUN!

Nombre común: D esconocido.

Registro departamental: CA.

Regiones Ecológicas: MA; 2150-2200 m. SINANPE: Sin registro.

Herbarios penuanos: CPUN (isotipo+1).

Observaciones: Hierba localmemte escasa, conocida de unas pocas localidades en una subcuenca del Crisnejas. Al parecer, no ha vuelto a ser recolectada desde 1982.

\section{Galactia fiebrigiana Burkart var. pedicellata Burkart}

Publicación: Darwiniana 16(3-4): 701. 1971.

Colección tipo: P.C. Hutchison 1505

Herbarios:

Nombre común: D esconocido.

Registro departamental: AM.

Regiones Ecológicas: Sin datos; altitud desconocida.

SINANPE: Sin registro.

Herbarios peruanos: Ninguno.

Observaciones: Este taxón fue considerado por Brako \& Zarucchi (1993) como un endemismo; sin embargo, no ha sido posible evaluarlo, ni asignarle una categoría.

71. Galactia killipiana J.F. Macbr.

\section{DD}

Publicación: Field Mus. Nat. Hist., Bot. Ser. 13(3/1): 333. 1943.

Colección tipo: E.P. Killip \& A.C. Smith 30675

Herbarios: NY, US.

Nombre común: D esconocido.

Registro departamental: JU.

Regiones Ecológicas: BMHP; $700 \mathrm{~m}$.

SINAN PE: Sin registro.

Herbarios peruanos: Ninguno.

Observaciones: Bejuco conocido solamente de la cuenca del Tulumayo. Al parecer, no ha vuelto a ser recolectado desde 1923.

72. Hoffmannseggia miranda Sandw.

$$
\text { EN, Blab(iii) }
$$

Publicación: Bull. Misc. Inform. Kew 1934(3): 99-100. 1934.

Colección tipo: D. Stafford K-53

Hembarios: $\mathrm{K}$.

Nombre común: D esconocido.

Registro departamental: AR, MO.

Regiones Ecológicas: DST; $100 \mathrm{~m}$.

SINAN PE: Sin registro.

Herbarios peruanos: USM (1)

Observaciones: Arbusto, conocido de unas pocas localidades aisladas, en la franja desértica costera del sur del país. Esta especie ha sido recolectada durante el desarrollo de la vegetación asociada a las garúas invernales. 
73. Hoffmannseggia viscosa (Ruiz \& Pav.) Hook. \& Arn. var. egenaJ.F. Macbr.

DD

Publicación: Publ. Field Columbian Mus., Bot. Ser. 8(2): 93-94. 1930.

Colección tipo: A. Weberbauer 7419a

Herbarios: $F$.

Nombre común: D esconocido.

Registro departamental: AR, MO.

Regiones Ecológicas: MA; $2100 \mathrm{~m}$.

SINANPE: Sin registro.

Herbarios peruanos: Ninguno.

Observaciones: Arbusto conocido del sur del país, de aparentemente dos localidades. El ejemplar tipo fue recolectado en 1925. Jørgensen \& León Yánez (1999) incluyen a la especie para Ecuador, sin considerar variedades. Este taxón requiere una evaluación taxonómica.

\section{Inga augusti $\mathrm{H}$ arms}

\section{DD}

Publicación: Repert. Spec. Nov. Regni Veg. 16: 245. 1919.

Colección tipo: A. Weberbauer 6705

Herbarios:

Nombre común: D esconocido.

Registro departamental: $\mathrm{HU}$.

Regiones Ecológicas: BS; $2500 \mathrm{~m}$.

SINANPE: Sin registro.

Herbarios peruanos: Ninguno.

Observaciones: Árbol conocido de bosques esclerófilos, en dos localidades del centro oriente del país. Según Reynel \& Pennington (1997), pertenece al grupo de Inga umbellifera. Aparentemente no ha vuelto a ser recolectada desde la década de 1920.

\section{Inga cynometrifolia Harms}

\section{EN, Bla}

Publicación: Verh. Bot. Vereins Prov. Brandenburg 48: 159. 1907.

Colección tipo: E.H.G. Ule 6452

Herbarios: K, MO.

Nombre común: Desconocido.

Registro departamental: SM.

Regiones Ecológicas: BHA; $260 \mathrm{~m}$.

SINANPE: Sin registro.

Herbarios penuanos: MOL (1).

Observaciones: Árbol conocido solamente de dos localidades en el nor-oriente del país, de la cuenca del Huallaga. Las colecciones conocidas datan de inicios del siglo XX.

76. Inga fosteriana T.D. Penn.

$$
\text { EN, Bla }
$$

Publicación: Gen. Inga Bot. 582. 1997.

Colección tipo: R.B. Foster et al. 3254

Hembarios: $F, K$.

Nombre común: D esconocido.

Registro departamental: MD.

Regiones Ecológicas: BHA; altitud desconocida.

SINAN PE: PNM

Herbarios peruanos: Ninguno.
Observaciones: Árbol conocido aparentemente sólo dela colección tipo, una planta recolectada en la cuenca del Alto Madre de Dios, en el Parque Nacional Manu.

\section{Ingagereauana (Pipoly \& Rodolfo Vásquez)T.D. Penn.}

EN, Bla

Publicación: Gen. Inga Bot. 781. 1997.

Colección tipo: R. Vásquez et al. 14326

Herbarios: F, G, K, MO, NY, US; AMAZ,

USM.

Nombre común: D esconocido.

Registro departamental: LO.

Regiones Ecológicas: BHA; 128-140 m. SINAN PE: Sin registro.

Herbarios peruanos: AMAZ (isotipo citado), USM (isotipo citado).

Observaciones: Árbol dehasta $12 \mathrm{~m}$, conocido deunas dospoblaciones en bosques no inundables en la cuenca del Amazonas. Esta especie fue incluida por Vásquez (1997) como A ffonsea gereeuna.

\section{Inga killipiana J.F. Macbr.}

Publicación: Field Mus. Nat. Hist., Bot. Ser. 13(3/ 1): 26. 1943.

Colección tipo: G. Klug 3743

Herbarios: F, US.

Nombre común: D esconocido.

Registro departamental: CU, PA, SM.

Regiones Ecológicas: BMHP; 1100 m.

SINANPE: Sin registro.

Henbarios peruanos: Ninguno.

Observaciones: Este taxón fue considerado por Brako \& Zarucchi (1993) como un endemismo; sin embargo, no ha sido posible evaluarlo, ni asignarle una categoría.

\section{Inga lineata Benth.}

\section{VU, Bla}

Publicación: London J. Bot. 4: 594. 1845.

Colección tipo: A. Mathews 1594

Herbarios:

Nombre común: D esconocido.

Registro departamental: $\mathrm{AM}, \mathrm{HU}, \mathrm{LO}$, PA, SM.

Regiones Ecológicas: BHA; 850-1000 m.

SINAN PE: Sin registro.

Hemarios penuanos: HAO (1).

Observaciones: Árbol conocido de bosques inundables y secundarios en varias localidades dispersas en la Amazonía peruana. El ejemplar tipo fue recolectado en el siglo XIX de los alrededores de Tarapoto. Según Reynel \& Pennington (1997) está pobremente recolectada.

\section{Inga longipes Benth.}

Publicación: Trans. Linn. Soc. London 30(3): 617. 1875.

Colección tipo: R. Spruce 4835

Herbarios: K, NY.

Nombre común: D esconocido.

Registro departamental: LO, SM, UC.

Regiones Ecológicas: BHA; $122-400$ m.

SINAN PE: PNM

Herbarios peruanos: Ninguno. 
Observaciones: Este taxón fue considerado por Brako \& Zarucchi (1993) como un endemismo; sin embargo, no ha sido posible evaluarlo, ni asignarle una categoría.

\section{Inga maynensis Benth.}

\author{
NT \\ Publicación: Trans. Linn. Soc. London \\ 30(3): 613. 1875. \\ Colección tipo: E.F. Poeppig s.n. \\ Hemarios: W. \\ Nombre común: D esconocido. \\ Registro departamental: LO. \\ Regiones Ecológicas: BHA; 100-150 m \\ SINAN PE: Sin registro. \\ Hemarios peruanos: AMAZ (2).
}

Observaciones: Árbol conocido de varias localidades, en las subcuencas del Amazonas y del Ucayali. Esta especie aparentemente está limitada a zonas ribereòas inundables (Reynel \& Pennington, 1997).

\section{Inga megalobotrys T.D. Penn.}

\section{EN, Bla}

Publicación: Gen. Inga Bot. 580. 1997.

Colección tipo: P. Núñez et al. 11237

Herbarios: K, MEXU, MO ; CUZ.

Nombre común: D esconocido.

Registro departamental: MD.

Regiones Ecológicas: BHA; $400 \mathrm{~m}$.

SINANPE: Sin registro.

Herbarios peruanos: CUZ (isotipo citado+1).

Observaciones: Árbol pequeño conocido de unas pocas colecciones, todas provenientes del Parque Nacional Manu.

\section{Inga pluricarpellata T.D. Penn.}

\section{EN, Bla}

Publicación: Gen. Inga Bot. 586. 1997.

Colección tipo: S. Knapp 8179

Herbarios: CM.

Nombre común: D esconocido.

Registro departamental: HU, SM.

Regiones Ecológicas: BHA; 200-300 m.

SINANPE: Sin registro.

Hemarios peruanos: Ninguno.

Observaciones: Según Reynel \& Pennington (1997), esta especie arbórea es conocida solamente de dos localidades. Estas se hallan en la cuenca del Huallaga.

\section{Inga tenuicalyx T.D. Penn.}

$$
\text { EN, Bla }
$$

Publicación: Gen. Inga Bot. 426. 1997.

Colección tipo: T.D. Pennington et al. 12368

Herbarios: K; MOLF.

Nombre común: D esconocido.

Registro departamental: SM.

Regiones Ecológicas: BS; $300 \mathrm{~m}$.

SINAN PE: Sin registro.

Herbarios peruanos: MOLF (isotipo).

Observaciones: Árbol descrito de una planta recolectada en 1989. Reynel \& Pennington (1997) señalan que esta especie sólo se conoce de los bosques secos cerca de Tarapoto, los cuales han sido escasamente herborizados.

\section{Jacqueshuberia lonetensis R.S. Cowan}

$$
\text { EN, Bla }
$$

Publicación: Brittonia 37(3): 294. 1985. Colección tipo: A.H. Gentry et al. 15778 Herbanios: COL, F, G, INPA, K, MO, NY, US; AMAZ!, USM.

Nombre común: D esconocido. Registro departamental: LO.

Regiones Ecológicas: BHA; altitud desconocida.

SINANPE: RNAM

Herbarios peruanos: AMAZ (isotipo), USM (tipo citado).

Observaciones: Esta especie arbórea es conocida de la Amazonía peruana. Fue descrita de una recolecta realizada en las cercanías de la Reserva Nacional Allpahuayo-Mishana.

\section{Lecointea ovalifolia J.F. Macbr.}

Publicación: Field Mus. Nat. Hist., Bot. Ser. 13(3/ 1): 220. 1943.

Colección tipo: G. Klug 3853

Herbarios:

Nombre común: D esconocido.

Registro departamental: SM.

Regiones Ecológicas: Sin datos; altitud desconocida.

SINANPE: Sin registro.

Herbarios peruanos: Ninguno.

Observaciones: Este taxón fue considerado por Brako \& Zarucchi (1993) como un endemismo; sin embargo, no ha sido posible evaluarlo, ni asignarle una categoría.

\section{Lupinus acopalcus C.P. Sm.}

\section{EN, Blab(iii)}

Publicación: Sp. Lupinorum 44: 754. 1953.

Colección tipo: C. O choa 996

Herbarios: MOL!.

Nombre común: D esconocido.

Registro departamental: JU.

Regiones Ecológicas: MA, PSH; 3400$3700 \mathrm{~m}$.

SINAN PE: Sin registro.

Herbarios peruanos: MOL (isotipo).

Observaciones: Hierba terrestre conocida solamente del tipo recolectado en el valle de Acopalca. Posiblemente el hábitat de esta especie sean laderas con matorrales en la zona ecotonal mesoandina y de la puna.

\section{L upinus adinoanthus C.P. Sm.}

$$
\text { EN, Blab(iii) }
$$

Publicación: Sp. Lupinorum 34: 595596. 1948.

Colección tipo: C. Vargas C. 4888

Hemarios: Sin datos.

Nombre común: D esconocido.

Registro departamental: CU.

Regiones Ecológicas: Sin datos; $3600 \mathrm{~m}$.

SINAN PE: Sin registro.

Herbarios peruanos: Ninguno. 
Observaciones: Esta hierba terrestre se conoce solamente de la colección tipo proveniente de la cuenca del Yavero. Aparentemente no ha vuelto a ser recolectada desde la década de 1940.

\section{Lupinus albert-smithianus C.P. Sm.}

$$
\text { VU, B1ab(iii), D2 }
$$

Publicación: Sp. Lupinorum 18: 279. 1941. Colección tipo: E.P. Killip \& A.C. Smith 24196 Henbarios: F, NY, US.

Nombre común: D esconocido.

Registro departamental: JU, PI. Regiones Ecológicas: BMHM; 1800$2700 \mathrm{~m}$.

SINANPE: Sin registro.

Herbarios peruanos: USM (1).

Observaciones: Este arbusto es conocido de dos localidades aisladas entre ellas por más de $500 \mathrm{~km}$. Morfológicamente asemeja a otras especies recolectadas en o los alrededores de la misma localidad, como L upinus carpapatiaus, L. disjunctus, L. ellsworthianus y L. tarmaensis.

\section{Lupinus alibicolorC.P. Sm.}

$$
\text { EN, Blab(iii) }
$$

Publicación: Sp. Lupinorum 44: 756. 1953.

Colección tipo: C. O choa 1467

Hemarios: US; MOL!.

Nombre común: D esconocido.

Registro departamental: LL.

Regiones Ecológicas: PSH; $3565 \mathrm{~m}$.

SINANPE: Sin registro.

Herbarios peruanos: MOL (isotipo).

Observaciones: Arbusto conocido solamente de la colección tipo, proveniente de la zona paramuna de La Libertad. Esta especie aparentemente no ha vuelto a ser recolectada desde 1952.

\section{L upinus alimanens C.P. Sm.}

\section{DD}

Publicación: Sp. Lupinorum 11: 162. 1940. Colección tipo: F. Herrera 57

Hemanios: D S.

Nombre común: D esconocido.

Registro departamental: CU.

Regiones Ecológicas: Sin datos; altitud desconocida.

SINANPE: Sin registro.

Herbarios peruanos: Ninguno.

Observaciones: Esta especie se conoce solamente de la colección tipo, desconociéndose la localidad exacta, hábitat y altitud. Aparentemente no ha vuelto a ser recolectada desde la década de 1920.

\section{Lupinus alinanus C.P. Sm.}

$$
\text { EN, Blab(iii) }
$$

Publicación: Sp. Lupinorum 31: 537538. 1945.

Colección tipo: C. Vargas C. 27

Herbarios: D S; CUZ.

Nombre común: Desconocido.

Registro departamental: CU.

Regiones Ecológicas: PSH; $3700 \mathrm{~m}$.

SINANPE: PNM

Herbarios penuanos: CUZ (tipo citado).
Observaciones: Esta especie se conoce solamente de la colección tipo, desconociéndose la localidad exacta, hábitat y altitud. Aparentemente, no ha vuelto a ser recolectada desde la década de 1930.

\section{Lupinus amboensis C.P. Sm.}

\section{DD}

Publicación: Sp. Lupinorum 44: 764. 1953.

Colección tipo: C. O choa 1109

Henbarios: D S.

Nombre común: D esconocido.

Registro departamental: $\mathrm{HU}$.

Regiones Ecológicas: MA; altitud desconocida.

SINAN PE: Sin registro.

Herbarios peruanos: Ninguno.

Observaciones: Esta especie se conoce solamente de la localidad original, en la cuenca alta del Huallaga Se desconoce detalles del hábitat. A parentemente no ha vuelto a ser recolectada desde 1951.

\section{Lupinus ampaiensis C.P. Sm.}

\section{CR, Bla}

Publicación: Sp. Lupinorum 35: 610611. 1948.

Colección tipo: C. Vargas C. 1025

Herbarios: D S.

Nombre común: Desconocido.

Registro departamental: AP.

Regiones Ecológicas: MA; altitud desconocida.

SINANPE: SNA

Herbarios peruanos: Ninguno.

Observaciones: Arbusto conocido dela colección tipo proveniente de un área protegida o sus alrededores. A parentemente no ha vuelto a ser recolectada desde fines de la década de 1930.

\section{Lupinus andinus Rose ex J.F. Macbr.}

$$
\text { CR, Blab(iii) }
$$

Publicación: Publ. Field Columbian Mus., Bot. Ser. 8(2): 95. 1930.

Colección tipo: J.F. Macbride \& W. Featherstone 884

Herbarios: $F$.

Nombre común: D esconocido.

Registro departamental: JU.

Regiones Ecológicas: AA; 4500 m.

SINANPE: Sin registro.

Herbarios peruanos: Ninguno.

Observaciones: Arbusto conocido de una localidad en el centro del país. A parentemente, no ha vuelto a ser recolectada desde 1922. Amenazas alas poblaciones están asociadas alosincendiosintencionales y actividades agropecuarias y mineras tan extendidas en la zona.

\section{L upinus antensis C.P. Sm.}

$$
\text { EN, B lab(iii) }
$$

Publicación: Sp. Lupinorum 33: 586587. 1948.

Colección tipo: C. Vargas C. 5486

Herbarios: MO.

Nombre común: D esconocido.

Registro departamental: CU.

Regiones Ecológicas: MA; 3000-3500 m.

SINANPE: Sin registro.

Herbarios peruanos: Ninguno. 
Observaciones: Subarbusto conocido solamente de una localidad en el sur del país. Aparentemente, no ha vuelto a ser recolectada desde la década de 1940.

\section{Lupinus appositus C.P. Sm.}

$$
\text { CR, B 1ab(iii) }
$$

Publicación: Sp. Lupinorum 10: 155. 1940.

Colección tipo: A. Mathews 479

Herbarios: $\mathrm{K}$.

Nombre común: D esconocido.

Registro departamental: LI.

Regiones Ecológicas: MA; 2700— 2800 m.

SINAN PE: Sin registro.

Herbarios peruanos: Ninguno.

Observaciones: Subarbusto conocido de una localidad en el valle del Chillón. Aparentemente, no ha vuelto a ser recolectada desde 1833. Presenta rango geográfico reducido y menor a $100 \mathrm{~km}^{2}$. Podría estar extinta, desde que esta localidad está empleada para actividades agrícolas.

\section{Lupinus arequipensis C.P. Sm.}

\section{CR, B lab(iii)}

Publicación: Sp. Lupinorum 18: 280. 1941.

Colección tipo: A.S. Hitchcock 22378

Hemarios: F, US.

Nombre común: D esconocido.

Registro departamental: AR.

Regiones Ecológicas: D ST; altitud desconocida.

SINANPE: Sin registro.

Herbarios peruanos: Ninguno.

Observaciones: Hierba terrestre, conocida de una localidad en el sur del país. Esta especie podría ser una planta anual dependiente de las estaciones delluvia. A parentemente, no havuelto a ser recolectada desde 1923. La localidad original podría estar amenazada por la expansión agrícola y urbana.

\section{Lupinus anizelus C.P. Sm.}

\section{DD}

Publicación: Sp. Lupinorum 34: 597. 1948.

Colección tipo: C. Vargas C. 5189

Henbarios: D S.

Nombre común: D esconocido.

Registro departamental: CU.

Regiones Ecológicas: Sin datos; altitud desconocida.

SINAN PE: Sin registro.

Henbarios peruanos: Ninguno.

Observaciones: Subarbusto conocido solamente de la colección tipo, de la que se desconocen la localidad exacta y hábitat.

\section{Lupinus asa-grayanus C.P. Sm.}

\section{EN, B 1ab(iii)}

Publicación: Sp. Lupinorum 17: 260. 1941.

Colección tipo: A. Cruckshanks s.n.

Herbarios: $\mathrm{K}$.

Nombre común: D esconocido.

Registro departamental: PA.

Regiones Ecológicas: PSH; altitud desconocida.

SINAN PE: Sin registro.

Herbarios peruanos: Ninguno.
Observaciones: Hierba o subarbusto conocido solamente de dos localidades en la cuenca alta del Chillón y herbonizadas en la década de 1830. Podńa estar representada en el Santuario Nacional de Huayllay.

\section{Lupinus asymbepus C.P. Sm.}

VU, B1ab(iii), D2

Publicación: Sp. Lupinorum 35: 613614. 1948.

Colección tipo: E. Nehmad 469

Herbarios: MO.

Nombre común: D esconocido.

Registro departamental: AP, CA.

Regiones Ecológicas: MA, PAR; 2980$3600 \mathrm{~m}$.

SINAN PE: Sin registro.

Herbarios penuanos: CPUN (1).

Observaciones: Esta especie herbácea es conocida solamente de la colección tipo y de una recolección adicional, de localidades distanciadas entre sí por más de $900 \mathrm{~km}$.

\section{Lupinus austrobicolorC.P. Sm.}

$$
\text { EN, Blab(iii) }
$$

Publicación: Sp. Lupinorum 44: 755756. 1953.

Colección tipo: C. O choa 1466

Herbarios: D S; MOL!

Nombre común: D esconocido.

Registro departamental: LL.

Regiones Ecológicas: MA; 3200 m.

SINANPE: Sin registro.

Herbarios peruanos: MOL (isotipo).

Observaciones: Esta especie herbácea 0 arbustiva es conocida solamente de la colección tipo, en la cuenca alta del río Moche. Presenta un rango geográfico potencialmente menor a $5000 \mathrm{~km}^{2}$.

\section{Lupinus austrosericeus C.P. Sm.}

EN, Blab(iii)

Publicación: Sp. Lupinorum 44: 765766. 1953.

Colección tipo: C. O choa 241

Herbarios: D S; MOL!

Nombre común: D esconocido.

Registro departamental: LI.

Regiones Ecológicas: PSH; $3773 \mathrm{~m}$.

SINAN PE: Sin registro.

Herbarios penuanos: MOL (isotipo).

Observaciones: Esta especie arbustiva es conocida solamente de la colección tipo, en la parte alta de la cuenca del nío Rímac. Presenta un rango geográfico potencialmente menor a $5000 \mathrm{~km}^{2}$. El isotipo depositado en MOL es muy parecido a $\mathrm{L}$ upinus ballianus, por lo que podría tratarse de la misma especie.

104. Lupinus barbatilabius C.P. Sm.

EN, Blab(iii)

Publicación: Sp. Lupinorum 44: 765. 1953.

Colección tipo: C. Ochoa 995

Herbarios: D S.

Nombre común: Desconocido.

Registro departamental: JU.

Regiones Ecológicas: MA; $3500 \mathrm{~m}$.

SINAN PE: Sin registro.

Herbarios peruanos: Ninguno. 
Observaciones: Esta especie es conocida sólo de la colección tipo proveniente de la cuenca alta del Mantaro, aunque se desconocen los datos del hábitat. Al parecer, no ha vuelto a ser recolectada desde 1951.

\section{Lupinus bi-inclinatus C.P. Sm.}

$$
\text { EN, Blab(iii) }
$$

Publicación: Sp. Lupinorum 31: 536. 1945.

Colección tipo: C. Vargas C. 1478

Herbarios: D S.

Nombre común: D esconocido.

Registro departamental: CU.

Regiones Ecológicas: PSH; $3860 \mathrm{~m}$.

SINANPE: Sin registro.

Herbarios peruanos: Ninguno.

Observaciones: Esta especie se conoce solamente del material tipo, recolectado en la cuenca del Apurímac. Aparentemente, no ha vuelto a ser recolectada desde 1939.

\section{Lupinus bombycinocarpus C.P. Sm.}

$$
\text { EN, Blab(iii) }
$$

Publicación: Sp. Lupinorum 34: 598. 1948.

Colección tipo: C. Vargas C. 5971

Herbarios: DS.

Nombre común: D esconocido.

Registro departamental: CU.

Regiones Ecológicas: MA; 3200-3600 m.

SINANPE: Sin registro.

Herbarios peruanos: Ninguno.

Observaciones: Esta especie arbustiva se conoce sólo del material tipo, en la cuenca del Urubamba. Aparentemente, no ha vuelto a ser recolectada desde la década de 1940.

\section{Lupinus brachypremnon C.P. Sm.}

\section{VU, Blab(iii)}

Publicación: Sp. Lupinorum 19: 294295. 1941.

Colección tipo: E.P. Killip \& A.C. Smith 23361

Hemarios: D S, NY, US.

Nombre común: D esconocido.

Registro departamental: AN, HU, JU, LI. Regiones Ecológicas: MA, PSH; 3300$4120 \mathrm{~m}$.

SINANPE: Sin registro.

Herbarios peruanos: USM (6).

Observaciones: Esta especie es conocida de las vertientes occidentales de los Andes centrales del país, en las cuencas del Chillón y del Mantaro.

\section{L upinus cachupatensis C.P. Sm.}

\section{EN, Blab(iii)}

Publicación: Sp. Lupinorum 31: 541. 1945.

Colección tipo: C. Vargas C. 2863

Herbarios: D S, GH.

Nombre común: D esconocido.

Registro departamental: CU.

Regiones Ecológicas: MA; $3500 \mathrm{~m}$.

SINANPE: Sin registro.

Herbarios peruanos: Ninguno.
Observaciones: Esta especie se conoce solamente del material tipo, recolectado hace más de 60 años en la cuenca del Paucartambo.

\section{L upinus calcensis C.P. Sm.}

$$
\text { EN, B lab(iii) }
$$

Publicación: Sp. Lupinorum 31: 541542. 1945.

Colección tipo: C. Vargas C. 3990

Herbarios: DS

Nombre común: D esconocido.

Registro departamental: CU.

Regiones Ecológicas: MA; $2600 \mathrm{~m}$.

SINAN PE: Sin registro.

Herbarios peruanos: Ninguno.

Observaciones: Esta especie se conoce solamente del material tipo, recolectado hace más de 60 años en la cuenca del Urubamba.

\section{Lupinus carazensis Ulbr.}

\section{EN, B 1ab(iii)}

Publicación: Bot. Jahrb. Syst. 37(5): 545. 1906.

Colección tipo: A. Weberbauer 3084

Hemarios: $B$.

Nombre común: D esconocido.

Registro departamental: AN.

Regiones Ecológicas: PSH; 3800-4200 m.

SINAN PE: Sin registro.

Herbarios peruanos: USM (1).

Observaciones: Esta especie subarbustiva es conocida de dos localidades situadas en la Cordillera Blanca, Ancash. Fue recolectada originalmente a inicios del siglo XX.

\section{Lupinus carhuamayus C.P. Sm.}

$$
\text { EN, B1ab(iii) }
$$

Publicación: Sp. Lupinorum 44: 761. 1953.

Colección tipo: C. O choa 1025

Herbarios: DS.

Nombre común: D esconocido.

Registro departamental: JU.

Regiones Ecológicas: PSH; $3700 \mathrm{~m}$.

SINAN PE: Sin registro.

Hembarios peruanos: Ninguno.

Observaciones: Esta especie herbácea o subarbustiva es conocida solamente de la localidad tipo, al norte de Junín. Es probable que se encuentre dentro de la Reserva Nacional de Junín.

\section{Lupinus carlos-ochoae C.P. Sm.}

$$
\text { EN, B 1ab(iii) }
$$

Publicación: Sp. Lupinorum 44: 760761. 1953.

Colección tipo: C. O choa 86

Herbarios: DS; USM!, MOL!.

Nombre común: D esconocido.

Registro departamental: JU.

Regiones Ecológicas: MA; 3400-3600 m.

SINANPE: Sin registro.

Herbarios peruanos: MOL (isotipo), USM (isotipo).

Observaciones: Esta especie herbácea o arbustiva se conoce sólo del material original, recolectado en la parte alta de la cuenca del Mantaro. 


\section{Lupinus carpapaticus C.P. Sm.}

$$
\text { EN, B1ab(iii) }
$$

Publicación: Sp. Lupinorum 12: 181. 1940. Colección tipo: E.P. Killip \& A.C. Smith 24360

Herbarios: D S, F.

Nombre común: D esconocido.

Registro departamental: JU.

Regiones Ecológicas: MA, BMHM; 2400 m.

SINAN PE: Sin registro.

Herbarios peruanos: Ninguno.

Observaciones: Esta especie arbustiva es conocida solamente de la localidad tipo, la cual ha sufrido procesos de deforestación y deslizamientos delas laderas. El isotipo deUS es similar en morfología a L upinus disjunctus, L . albert-smithianus y a L . tarmaensis, todas recolectadas entre Carpapata y Huacapistana.

\section{Lupinus ccorilazensis Vargas ex C.P. Sm.}

\section{EN, B lab(iii)}

Publicación: Sp. Lupinorum 33: 590591. 1948.

Colección tipo: C. Vargas C. 6575

Herbarios: DS.

Nombre común: D esconocido.

Registro departamental: CU.

Regiones Ecológicas: PSH, AA; 4100$4300 \mathrm{~m}$.

SINANPE: Sin registro.

Hemarios peruanos: Ninguno.

Observaciones: Esta especie subarbustiva es conocida solamente de la localidad tipo, situada en la cuenca alta del Apurímac. Aparentemente no ha vuelto a ser recolectada desde 1947.

\section{L upinus cesaranus C.P. Sm.}

\section{EN, B lab(iii)}

Publicación: Sp. Lupinorum 31: 537. 1945.

Colección tipo: C. Vargas C. 3323

Herbarios: DS.

Nombre común: D esconocido.

Registro departamental: CU.

Regiones Ecológicas: PSH; $4150 \mathrm{~m}$.

SINAN PE: Sin registro.

Herbarios peruanos: Ninguno.

Observaciones: Especie herbácea conocida solamente de la localidad tipo, situada en la cuenca alta del Urubamba.

116. Lupinus cesar-vargasiiC.P. Sm.

$$
\text { EN, B lab(iii) }
$$

Publicación: Sp. Lupinorum 31: 538. 1945.

Colección tipo: C. Vargas C. 3017

Herbarios: DS.

Nombre común: D esconocido.

Registro departamental: CU.

Regiones Ecológicas: BPM; $3400 \mathrm{~m}$.

SINAN PE: Sin registro.

Hemarios peruanos: Ninguno.

Observaciones: Especie herbácea conocida solamente de la localidad tipo, situada en la cuenca del Alto Madre de Dios. Esta localidad se halla en el borde del Parque Nacional Manu y es probable que poblaciones adicionales se encuentre allí.
117. Lupinus chachas Ochoa ex C.P. Sm.

EN, Blab(iii)

Publicación: Sp. Lupinorum 44: 758759. 1953.

Colección tipo: C. Ochoa 1668

Herbarios: D S; MOL!.

Nombre común: Desconocido.

Registro departamental: AM.

Regiones Ecológicas: BPM; $3000 \mathrm{~m}$.

SINANPE: Sin registro.

Herbarios peruanos: MOL (isotipo).

Observaciones: Especie arbustiva conocida solamente del material tipo, proveniente de la cuenca del Utcubamba. Probablemente se halle en ambientes ecotonales bosque-pajonal.

\section{Lupinus chavanillensis (J.F. Macbr.) C.P. Sm.}

$$
\text { EN, Blab(iii) }
$$

Publicación: Sp. Lupinorum 17: 269. 1941. Colección tipo: J.F. Macbride \& W. Featherstone 1963

Hembarios: $F$.

Nombre común: D esconocido.

Registro departamental: HU.

Regiones Ecológicas: MA; 2438 m.

SINAN PE: Sin registro.

Herbarios peruanos: Ninguno.

Observaciones: Especie arbustiva conocida solamente del material tipo, proveniente de la cuenca del Alto Marañón. Esta parte de la cuenca ha sido escasamente herborizada y tal vez esto contribuya a la aparente rareza de esta especie.

\section{Lupinus chongus-bajous C.P. Sm.}

$$
\text { EN, Blab(iii) }
$$

Publicación: Sp. Lupinorum 36: 631632. 1948.

Colección tipo: C. Vargas C. 6603

Herbarios: DS.

Nombre común: Desconocido.

Registro departamental: JU.

Regiones Ecológicas: MA, PSH; $3600 \mathrm{~m}$. SINANPE: Sin registro.

Herbarios peruanos: Ninguno.

Observaciones: Especie subarbustiva conocida solamente del material tipo, proveniente de la cuenca del Mantaro. Esta zona ha sido escasamente herborizada.

\section{Lupinus chrysanthus U lbrich}

VU, B1ab(iii), D2

Publicación: Bot. Jahrb. Syst. 37(5): 543544. 1906.

Colección tipo: A. Weberbauer 2891

Herbarios: $B, F$.

Nombre común: D esconocido.

Registro departamental: AN, LL.

Regiones Ecológicas: PSH, PAR; 3250$4100 \mathrm{~m}$.

SINAN PE: Sin registro.

Herbarios peruanos: Ninguno.

Observaciones: Esta especie de herbácea perenne es conocida solamente de dos colecciones, proveniente probablemente de las cuencas altas del Pativilca y Santa. 


\section{Lupinus chumbivilcensis C.P. Sm.}

$$
\text { EN, Blab(iii) }
$$

Publicación: Sp. Lupinorum 33: 590. 1948.

Colección tipo: C. Vargas C. 6576

Herbarios: D S.

Nombre común: D esconocido.

Registro departamental: CU.

Regiones Ecológicas: PSH; 3900-4200 m.

SINANPE: Sin registro.

Herbarios peruanos: Ninguno.

Observaciones: Especie subarbustiva conocida solamente del material tipo, encontrada en la cuenca del A purímac. No se conocen ejemplares de herbario adicionales desde la década de 1940.

\section{L upinus cochapatensis C.P. Sm.}

$$
\text { EN, Blab(iii) }
$$

Publicación: Sp. Lupinorum 35: 615616. 1948.

Colección tipo: C. Vargas C. 5788

Herbarios: D S.

Nombre común: D esconocido.

Registro departamental: AP.

Regiones Ecológicas: MA; $3300 \mathrm{~m}$.

SINAN PE: Sin registro.

Herbarios peruanos: Ninguno.

Observaciones: Especie subarbustiva conocida solamente del material tipo, encontrada en la cuenca del Apurímac.

\section{Lupinus colcabambensis C.P. Sm.}

$$
\text { EN, Blab(iii) }
$$

Publicación: Sp. Lupinorum 44: 764. 1953.

Colección tipo: C. Vargas C. 988

Herbarios: D S.

Nombre común: D esconocido.

Registro departamental: HV.

Regiones Ecológicas: MA; 2200 m.

SINAN PE: Sin registro.

Herbarios peruanos: Ninguno.

Observaciones: Especie arbustiva conocida solamente del material tipo, proveniente de la cuenca del Mantaro.

\section{Lupinus condensiflorus C.P. Sm.}

\section{NT}

Publicación: Sp. Lupinorum 10: 154. 1940.

Colección tipo: F.W. Pennell 13565

Herbarios: K, NY, US; USM!.

Nombre común: D esconocido.

Registro departamental: AY, CU, JU, LI. Regiones Ecológicas: PSH; 3250-4000 m.

SINAN PE: Sin registro.

Herbarios peruanos: MOL (1), USM (isotipo+9).

Observaciones: Especie subarbustiva fue inicialmente recolectada en el valle del Urubamba. Su rango de distribución se extiende a la región central del país, tanto en valles interandinos como del Mantaro como en las vertientes del Pacífico, de la cuenca del Chillón.
125. Lupinus convencionensis C.P. Sm.

$$
\text { EN, Blab(iii) }
$$

Publicación: Sp. Lupinorum 31: 540. 1945.

Colección tipo: C. Vargas C. 3427

Herbarios: D S.

Nombre común: D esconocido.

Registro departamental: CU.

Regiones Ecológicas: BMHP; 1500 m.

SINANPE: Sin registro.

Herbarios peruanos: Ninguno.

Observaciones: Esta especie herbácea es conocida sólo de la colección tipo, recolectada en el valle del Urubamba.

\section{Lupinus cookianus C.P. Sm.}

\section{CR, Blab(iii)}

Publicación: Sp. Lupinorum 10: 160. 1940. Colección tipo: O.F. Cook \& G.B. Gilbert 1140

Hemarios: US.

Nombre común: Qquera.

Registro departamental: $\mathrm{CU}$.

Regiones Ecológicas: $\mathrm{BMHM}$; altitud desconocida.

SINANPE: Sin registro.

Hembarios peruanos: Ninguno.

Observaciones: Especie subarbustiva conocida sólo de la colección tipo, recolectada en el valle del Urubamba. Probablemente se encuentre dentro del Santuario Histórico Machu Picchu. Brako \& Zarucchi (1993) citaron un ejemplar de Amazonas, pero no pudo verificarse y aquí se restringe la distribución de esta especie solamente al sur del país.

\section{Lupinus cuzcensis C.P. Sm.}

$$
\text { VU, B 1ab(iii) }
$$

Publicación: Sp. Lupinorum 17: 267. 1941. Colección tipo: F.W. Pennell 13516

Hemarios: $\mathrm{GH}$.

Nombre común: Flor de chapra.

Registro departamental: CU, LI. Regiones Ecológicas: PSH, AA; 3800$4500 \mathrm{~m}$.

SINANPE: Sin registro.

Herbarios peruanos: USM (1).

Observaciones: Especie herbácea conocida solamente para Cusco y Lima, en las partes altas de las cuencas del Urubamba y Cañete, respectivamente. La última recolecta data de hace más de 50 años.

\section{Lupinus cymboidesC.P. Sm.}

$$
\text { VU, Blab(iii), D2 }
$$

Publicación: Sp. Lupinorum 17-19: 265. 1941. Colección tipo: E.P. Killip \& A.C. Smith 22139 Hemarios: DS, NY, US.

Nombre común: D esconocido.

Registro departamental: HV, JU, LI. Regiones Ecológicas: MA, PSH; 3400$4220 \mathrm{~m}$.

SINANPE: Sin registro.

Hembarios peruanos: MOL (1), USM (5).

Observaciones: Hierba terrestre conocida de al menos cuatro localidades en los Andes centrales del país. Estas localidades están en las cuencas del Mantaro y Chillón. 


\section{Lupinus diasemusC.P. Sm.}

\section{EN, Blab(iii)}

Publicación: Sp. Lupinorum 36: 629- 630. 1948.

Colección tipo: C. Vargas C. 6604

Herbarios: D S.

Nombre común: D esconocido.

Registro departamental: PA.

Regiones Ecológicas: MA, PSH; 4400$4500 \mathrm{~m}$.

SINANPE: Sin registro.

Herbarios peruanos: Ninguno.

Observaciones: Especie herbácea conocida solamente de la localidad tipo, en la cuenca del Alto Huallaga. Aparentemente no ha vuelto a ser recolectada desde 1947.

\section{L upinus disjunctus C.P. Sm.}

\section{EN, B lab(iii)}

Publicación: Sp. Lupinorum 18: 284. 1941.

Colección tipo: E.P. Killip \& A.C. Smith 24237

Herbarios: D S, NY, US.

Nombre común: D esconocido.

Registro departamental: JU.

Regiones Ecológicas: BMHM; 1800$2400 \mathrm{~m}$.

SINANPE: Sin registro.

Hemarios peruanos: Ninguno.

Observaciones: Especie herbácea o subarbustiva conocida solamente del material tipo, en la cuenca del Perené. El isotipo depositado en US es similar en morfología a L upinus carpapatiaus, L . ellsworthianus, L . albert-smithianus y L . tarmaensis, todas recolectadas entre Carpapata y Huacapistana.

\section{Lupinus doraevar. paucoflorus C.P. Sm. var.} paucoflorus C.P. Sm.

\section{DD}

Publicación: Sp. Lupinorum 35: 618. 1948. Colección tipo: H.E. Stork \& O.B. Horton 10847

Herbarios: UC.

Nombre común: D esconocido.

Registro departamental: HV.

Regiones Ecológicas: PSH; 3900 m.

SINAN PE: Sin registro.

Herbarios peruanos: Ninguno.

Observaciones: Especie de la cual se desconoce localidad y hábitat específicos, aunque probablemente provenga de Tayacaja, cuenca del Mantaro.

132. Lupinus eanophyllus C.P. Sm.

\section{EN, B lab(iii)}

Publicación: Sp. Lupinorum 44: 763. 1953.

Colección tipo: C. O choa 1060

Herbarios: D S.

Nombre común: D esconocido.

Registro departamental: HU.

Regiones Ecológicas: BMHM; 2200 m.

SINAN PE: Sin registro.

Herbarios peruanos: Ninguno.
Observaciones: Especie herbácea conocida solamente del material original, recolectado en Carpish, cuenca del Huallaga. Esta localidad presenta alto endemismo y por tanto es de interés para la conservación. Al igual que otras especies endémicas de estalocalidad se necesita confirmar su presencia y para ello es importante continuar las evaluaciones florísticas.

133. Lupinus edysomatus C.P. Sm.

$$
\text { VU, B1ab(iii), D2 }
$$

Publicación: Sp. Lupinorum 35: 614. 1948.

Colección tipo: E. Nehmad 470

Herbarios: D S, MO.

Nombre común: D esconocido.

Registro departamental: AP, CU, LI.

Regiones Ecológicas: MA, BPM, BMHM; $1800-4600 \mathrm{~m}$

SINAN PE: Sin registro.

Herbarios peruanos: Ninguno.

Observaciones: Especie subarbustiva conocida sólo en algunos valles interandinos y bosques montanos de las regiones centro y sur del país.

\section{Lupinus egens C.P. Sm.}

$$
\text { EN, Blab(iii) }
$$

Publicación: Sp. Lupinorum 35: 617618. 1948.

Colección tipo: H.E. Stork \& O.B. Horton 10864

Herbarios: UC.

Nombre común: D esconocido.

Registro departamental: HV.

Regiones Ecológicas: MA; 3500 m.

SINAN PE: Sin registro.

Herbarios peruanos: Ninguno.

Observaciones: Especie herbácea o subarbustiva conocida solamente del material tipo, recolectado en la cuenca del Mantaro. Aparentemente no ha vuelto a ser recolectada desde la década de 1930.

\section{Lupinus ellsworthianus C.P. Sm.}

$$
\text { CR, Blab(iii) }
$$

Publicación: Sp. Lupinorum 10: 159. 1940. Colección tipo: E.P. Killip \& A.C. Smith 24338 Herbarios: US.

Nombre común: D esconocido.

Registro departamental: JU.

Regiones Ecológicas: MA, BMHM; 2400 m. SINAN PE: Sin registro.

Herbarios peruanos: USM (2).

Observaciones: Especie arbustiva conocida solamente para la región central del país, en la cuenca del Perené. El holotipo depositado en US es similar en morfología a L upinus carpapatiaus, L. disjunctus, L . albert-smithianus y L . tarmaensis, todas recolectadas entre Carpapata y Huacapistana.

\section{Lupinus espinarensis C.P. Sm.}

$$
\text { EN, Blab(iii) }
$$

Publicación: Sp. Lupinorum 33: 586. 1948.

Colección tipo: C. Vargas C. 5594

Herbarios: D S.

Nombre común: D esconocido.

Registro departamental: $\mathrm{CU}$.

Regiones Ecológicas: PSH; 3895 m.

SINANPE: Sin registro.

Herbarios peruanos: Ninguno. 
Observaciones: Especie subarbustiva conocida solamente de la localidad tipo en la cuenca del Apurímac. Aparentemente no ha vuelto a ser recolectada desde 1946. La zona requiere más estudios botánicos. Por el rango altitudinal y caractenísticas del ambiente, probablemente actividades mineras podrín ser problemáticas para esta especie.

\section{Lupinus exochus C.P. Sm.}

\section{LC}

Publicación: Sp. Lupinorum 19: 291292. 1941.

Colección tipo: E.P. Killip \& A.C. Smith 21724

Herbarios: DS, MO, US.

Nombre común: D esconocido.

Registro departamental: AN, CU, LI.

Regiones Ecológicas: MA, PSH; 2900$3900 \mathrm{~m}$.

SINAN PE: Sin registro.

Hemarios peruanos: USM (7).

Observaciones: Especie arbustiva conocida de valles interandinos y puna del centro y sur del país. Es conocida de por lo menos 12 localidades, constituyendo así la especie endémica con mayor distribución dentro del género.

\section{L upinus falsomutabilisC.P. Sm.}

\section{EN, Blab(iii)}

Publicación: Sp. Lupinorum 44: 763. 1953.

Colección tipo: C. O choa 431

Herbarios: D S.

Nombre común: D esconocido.

Registro departamental: HU.

Regiones Ecológicas: BMHM; $2000 \mathrm{~m}$.

SINAN PE: Sin registro.

Herbarios peruanos: Ninguno.

Observaciones: Especie arbustiva conocida solamente de la localidad tipo, en la cuenca del Huallaga.

139. Lupinus falsoprostratus C.P. Sm.

$$
\text { EN, Blab(iii) }
$$

Publicación: Sp. Lupinorum 36: 631. 1948.

Colección tipo: E.P. Killip \& A.C. Smith 23352

Herbarios: D S, US.

Nombre común: D esconocido.

Registro departamental: JU.

Regiones Ecológicas: MA; 3300-3500 m.

SINANPE: Sin registro.

Hembarios peruanos: Ninguno.

Observaciones: Especie herbácea solamente conocida del material tipo, recolectado en cercanías de la capital del D epartamento, cuenca del Mantaro.

\section{Lupinus fieldii Rose ex J.F. Macbr.}

$$
\text { EN, Blab(iii) }
$$

Publicación: Publ. Field Columbian Mus., Bot. Ser. 8(2): 94-95. 1930.

Colección tipo: J.F. Macbride 876

Herbarios: F, US.

Nombre común: D esconocido.

Registro departamental: JU.

Regiones Ecológicas: AA; $4572 \mathrm{~m}$.

SINANPE: Sin registro.

Herbarios peruanos: Ninguno.
Observaciones: Especie herbácea conocida sólo del material tipo, recolectado en la cuenca alta del Mantaro. Aparentemente no ha vuelto a ser recolectada. La localidad tipo está afectada por el pastoreo y la minería.

\section{Lupinus francis-whittieniC.P. Sm.}

$$
\text { EN, B lab(iii) }
$$

Publicación: Sp. Lupinorum 18: 282283. 1941.

Colección tipo: F.W. Pennell 14114

Herbarios: GH, NY.

Nombre común: D esconocido.

Registro departamental: CU.

Regiones Ecológicas: BPM; 3000-3300 $\mathrm{m}$.

SINANPE: Sin registro.

Herbarios peruanos: Ninguno.

Observaciones: Esta especie herbácea o subarbustiva se conoce sólo del material tipo, recolectado en la cuenca media del Yavero. Esta localidad se halla adyacente al Parque Nacional Manu y es probable que esté representada allí. En Macbride (1948: 480), el ejemplar Macbride 4079 es referido a L upinus lindleyanus y no a esta entidad, por lo que aquí se excluye el registro en Huánuco, citado por Brako \& Zarucchi (1993).

\section{Lupinus gaudichaudianus C.P. Sm.}

$$
\text { CR, B lab(iii) }
$$

Publicación: Sp. Lupinorum 19: 289290. 1941.

Colección tipo: A. Gaudichaud s.n.

Herbarios: P.

Nombre común: D esconocido.

Registro departamental: LI.

Regiones Ecológicas: DST; altitud desconocida.

SINANPE: Sin registro.

Hembarios peruanos: Ninguno.

Observaciones: Esta especie herbácea es conocida solamente del material original, cuya localidad es señalada a nivel del mar. Esta, junto con otras tres especies, son las únicas que habitan ambientes de la costa peruana. Weberbauer (1945) menciona que G audichaud recolectó en 1836 en Piura, por lo que la localidad original, atribuida a Lima, queda en duda.

\section{Lupinus gayanus C.P. Sm.}

\section{DD}

Publicación: Sp. Lupinorum 11: 173. 1940.

Colección tipo: C. Gay s.n.

Herbarios: $\mathrm{GH}$.

Nombre común: D esconocido.

Registro departamental: CU.

Regiones Ecológicas: Sin datos; altitud desconocida.

SINAN PE: Sin registro.

Herbarios peruanos: Ninguno.

Observaciones: Especie arbustiva conocida solamente del material tipo, recolectado en Cusco, sin datos específicos de localidad y hábitat. 
144. Lupinus goodspeedii J.F. Macbr.

$$
\text { EN, B1ab(iii) }
$$

Publicación: Field Mus. Nat. Hist., Bot. Ser. 13(3/ 1): 481-482. 1943.

Colección tipo: H.E. Stork \& O.B. Horton 9944

Herbanios: UC.

Nombre común: Chugur, chochillo silvestre.

Registro departamental: LL.

Regiones Ecológicas: MA; 3000-3600

$\mathrm{m}$.

SINANPE: Sin registro.

Herbarios penuanos: HUT (4).

Observaciones: Subarbusto conocido solamente de la vertiente occidental en el sur de La Libertad en la cuenca del Tablachaca, afluente del Santa. Varios ejemplares de herbario recolectados durante los 1970 y 1980 parecen provenir de poblaciones vecinas.

\section{L upinus grauensis C.P. Sm.}

\section{EN, B 1ab(iii)}

Publicación: Sp. Lupinorum 35: 615. 1948.

Colección tipo: C. Vargas C. 5767

Hembarios: D S.

Nombre común: D esconocido.

Registro departamental: AP.

Regiones Ecológicas: PSH; 3850 m.

SINAN PE: Sin registro.

Herbarios peruanos: Ninguno.

Observaciones: Esta especie herbácea es conocida solamente del material tipo, recolectado hace casi 60 años, en la parte alta de la cuenca del Apurímac.

146. Lupinus hamaticalyx C.P. Sm.

$$
\text { EN, B1ab(iii) }
$$

Publicación: Sp. Lupinorum 11: 166167. 1940.

Colección tipo: A. Mathews s.n.

Herbarios: D S.

Nombre común: Chocho.

Registro departamental: AM, LL.

Regiones Ecológicas: MA, BMHM; 3400

$\mathrm{m}$.

SINAN PE: Sin registro.

Hemarios penuanos: HUT (1).

Observaciones: Arbusto conocido solamente de dos colecciones al norte del país, una de ellas en la cuenca del Marañón. El ejemplar tipo fue recolectado en 1835. El ejemplar de herbario más reciente que se consultó fue recolectado en la década de 1960.

\section{Lupinus hautcarazensis C.P. Sm.}

\section{EN, B 1ab(iii)}

Publicación: Sp. Lupinorum 44: 759760. 1953.

Colección tipo: C. Ochoa 1460

Herbarios: D S.

Nombre común: Desconocido.

Registro departamental: LL.

Regiones Ecológicas: MA; $3000 \mathrm{~m}$.

SINAN PE: Sin registro.

Herbarios peruanos: Ninguno.
Observaciones: Esta especie arbustiva es conocida solamente de la colección tipo, proveniente de la parte alta de la cuenca del Moche. La localidad original está afectada por la minería y el pastoreo intensivo.

148. Lupinus herreranus C.P. Sm.

$$
\text { EN, Blab(iii) }
$$

Publicación: Sp. Lupinorum 19: 293. 1941. Colección tipo: F. Herrera 2093

Henbarios: D S, US.

Nombre común: D esconocido.

Registro departamental: CU.

Regiones Ecológicas: MA; $2760 \mathrm{~m}$.

SINAN PE: Sin registro.

Herbarios peruanos: Ninguno.

Observaciones: Esta especie arbustiva es conocida solamente del tipo, aunque se carecen de los datos precisos de la localidad y hábitat.

\section{Lupinus hinkleyorum C.P. Sm.}

\section{EN, Blab(iii)}

Publicación: Sp. Lupinorum 12: 182183. 1940.

Colección tipo: F.E. Hinkley \& Hinkley 12

Herbarios: GH.

Nombre común: Esquera.

Registro departamental: AR.

Regiones Ecológicas: MA; 2440 m.

SINAN PE: Sin registro.

Herbarios peruanos: Ninguno.

Observaciones: Esta especie arbustiva es conocida solamente para Arequipa, aunque las únicas recolectas datan de inicios de 1920.

\section{Lupinus hortonianus C.P. Sm.}

$$
\text { EN, Blab(iii) }
$$

Publicación: Sp. Lupinorum 35: 617. 1948. Colección tipo: H.E. Stork \& O.B. Horton 10244

Herbarios: UC.

Nombre común: D esconocido.

Registro departamental: HV.

Regiones Ecológicas: MA; 3250 m.

SINAN PE: Sin registro.

Herbarios peruanos: Ninguno.

Observaciones: Esta especie subarbustiva es conocida sólo del material tipo, recolectado en la cuenca del Mantaro.

151. Lupinus huancayoensis C.P. Sm.

$$
\text { EN, Blab(iii) }
$$

Publicación: Sp. Lupinorum 36: 632633. 1948.

Colección tipo: J. Soukup 2963

Herbarios: US.

Nombre común: D esconocido.

Registro departamental: JU.

Regiones Ecológicas: MA; 3200-3800 m.

SINAN PE: Sin registro.

Herbarios peruanos: Ninguno.

Observaciones: Esta especie herbácea es conocida solamente del material tipo, recolectado en la cuenca del Mantaro. Aparentemente no havuelto a recolectarse desde la década de 1940. Probablemente las dificultades taxonómicas del género dificulta su reconocimiento y afecta el interés por este interesante género. 
152. Lupinus huariacus C.P. Sm.

$$
\text { EN, Blab(iii) }
$$

Publicación: Sp. Lupinorum 44: 756757. 1953.

Colección tipo: C. O choa 1112

Herbarios: D S.

Nombre común: D esconocido.

Registro departamental: PA.

Regiones Ecológicas: PSH; $3900 \mathrm{~m}$.

SINANPE: Sin registro.

Herbarios peruanos: Ninguno.

Observaciones: Esta especie herbácea es conocida solamente del material tipo, recolectado en la parte alta de la cuenca del Huallaga. La localidad original ha recibido escasa herborización. Esta zona está afectada por la actividad minera.

\section{L upinus huaronensisJ.F. Macbr. var. huaronensis}

$$
\text { EN, Blab(iii) }
$$

Publicación:

Colección tipo: J.F. Macbride \& W. Featherstone 1141

Herbarios: F, MO, US.

Nombre común: D esconocido.

Registro departamental: JU, LI, PA.

Regiones Ecológicas: PSH, AA; 4200$4620 \mathrm{~m}$

SINAN PE: Sin registro.

Hemarios peruanos: USM (1).

Observaciones: Este taxón es conocido solamente para las regiones altoandinas del centro del país. Macbride (1943) comentó la poca diferencia morfológica entre las variedades, por lo que se necesita aclarar el estatus de las variedades, así como sus vínculos con otras especies andinas.

154. Lupinus huaronensisJ.F. Macbr. var. pascoensisJ.F. Macbr.

$$
\text { EN, Blab(iii) }
$$

Publicación: Publ. Field Columbian Mus., Bot. Ser. 8(2): 96. 1930.

Colección tipo: J.F. Macbride 3056

Herbarios: $F$.

Nombre común: D esconocido.

Registro departamental: JU, PA.

Regiones Ecológicas: PSH; 4270—4700 m.

SINANPE: Sin registro.

Herbarios peruanos: Ninguno.

Observaciones: Taxón herbáceo conocido solamente de las zonas altoandinas del centro del país. Como se comenta para la variedad típica se requiere aclarar el estatus de variedad.

155. Lupinus inusitatus C.P. Sm.

$$
\text { EN, Blab(iii) }
$$

Publicación: Sp. Lupinorum 33: 591592. 1948.

Colección tipo: C. Vargas C. 6553

Herbarios: D S.

Nombre común: D esconocido.

Registro departamental: CU.

Regiones Ecológicas: PSH; 3720 m.

SINANPE: Sin registro.

Herbarios peruanos: Ninguno.
Observaciones: Esta especie subarbustiva es conocida sólo del material tipo, proveniente de la cuenca del Apurímac. Aparentemente no hay colecciones adicionales desde 1947. La localidad conocida además ha recibido escasa herborización.

\section{Lupinus james-westiiC.P. Sm.}

$$
\text { EN, B lab(iii) }
$$

Publicación: Sp. Lupinorum 36: 635. 1948.

Colección tipo: J. West 3639

Hemanios: UC.

Nombre común: D esconocido.

Registro departamental: AY.

Regiones Ecológicas: Sin datos; altitud desconocida.

SINAN PE: Sin registro.

Herbarios peruanos: Ninguno.

Observaciones: Esta especie herbácea es conocida solamente del tipo, recolectado en las alturas de Ayacucho.

\section{Lupinus jelskianus C.P. Sm.}

$$
\text { CR, Blab(iii) }
$$

Publicación: Sp. Lupinorum 11: 175. 1940.

Colección tipo: C. Jelski 211

Herbarios: B.

Nombre común: D esconocido.

Registro departamental: CA.

Regiones Ecológicas: MA; altitud desconocida.

SINANPE: Sin registro.

Herbarios peruanos: Ninguno.

Observaciones: Esta especie arbustiva es conocida solamente de la descripción del tipo, en la cuenca del Chamaya, no habiendo vuelto a ser recolectada desde entonces.

\section{L upinus kalenbornorum C.P. Sm.}

$$
\text { EN, Blab(iii) }
$$

Publicación: Sp. Lupinorum 17: 266267. 1941.

Colección tipo: M. Kalenborn \& A. Kalenborn 63

Herbarios: NY.

Nombre común: Desconocido.

Registro departamental: JU.

Regiones Ecológicas: PSH; altitud desconocida.

SINAN PE: Sin registro.

Herbarios peruanos: Ninguno.

Observaciones: Especie herbácea conocida solamente de la colección tipo, proveniente de la zona altoandina de Junín, en la cuenca del Mantaro. El pastoreo y la minería son actividades que podrían afectar las poblaciones de esta especie.

\section{Lupinus lechlerianus C.P. Sm.}

$$
\text { EN, B1ab(iii) }
$$

Publicación: Sp. Lupinorum 12: 184185. 1940.

Colección tipo: W. Lechler 1714

Hembarios: $\mathrm{K}$.

Nombre común: D esconocido.

Registro departamental: AR, PU.

Regiones Ecológicas: PSH; 4100 m.

SINANPE: Sin registro.

Herbarios peruanos: Ninguno. 
Observaciones: Especie subarbustiva conocida solamente de la colección tipo y de un ejemplar adicional en Arequipa. Aparentemente no ha vuelto a ser recolectada desde 1914

160. Lupinus ledigianus C.P. Sm.

EN, B 1ab(iii)

Publicación: Sp. Lupinorum 19: 294. 1941.

Colección tipo: P. Ledig 20

Hembarios: US.

Nombre común: D esconocido.

Registro departamental: JU.

Regiones Ecológicas: PSH; $4000 \mathrm{~m}$.

SINAN PE: Sin registro.

Herbarios peruanos: Ninguno.

Observaciones: Especie arbustiva conocida solamente de la colección tipo, proveniente de la cuenca del Mantaro.

161. Lupinus lorenzensis C.P. Sm.

\section{DD}

Publicación: Sp. Lupinorum 18: 280. 1941.

Colección tipo: A. Gaudichaud s.n.

Herbarios: B.

Nombre común: D esconocido.

Registro departamental: LI.

Regiones Ecológicas: D ST; altitud desconocida.

SINANPE: Sin registro.

Hemarios peruanos: Ninguno.

Observaciones: Esta especie herbácea es conocida sólo de la descripción original, en donde se cita la isla San Lorenzo, frente al Callao, como la localidad tipo. Weberbauer (1945) menciona que Gaudichaud estuvo recolectando plantas en la costa de Lima y Piura. Es probable que el ejemplar de Gaudichaud represente una planta que se estableció fortuitamente en la vegetación estacional y efímera de esa isla.

\section{Lupinus macbrideanus C.P. Sm.}

$$
\text { EN, B1ab(iii) }
$$

Publicación: Sp. Lupinorum 10: 159160. 1940.

Colección tipo: J.F. Macbride 3464

Herbarios: F, US.

Nombre común: Desconocido.

Registro departamental: $\mathrm{HU}$.

Regiones Ecológicas: MA; $2590 \mathrm{~m}$.

SINANPE: Sin registro.

Herbarios peruanos: Ninguno.

Observaciones: Esta especie arbustiva es conocida solamente para la región central del país, cuenca del Huallaga.

\section{Lupinus malacotrichus C.P. Sm.}

\section{DD}

Publicación: Sp. Lupinorum 17: 263. 1941.

Colección tipo: R.W. Pearce s.n.

Herbarios: $\mathrm{K}$.

Nombre común: D esconocido.

Registro departamental: HV.

Regiones Ecológicas: Sin datos; altitud desconocida.

SINAN PE: Sin registro.

Herbarios peruanos: Ninguno.
Observaciones: Especie herbácea conocida solamente de la descripción original, cuya localidad no se precisa con claridad; probablemente se trate de Huaytará.

164. Lupinus maleopinatusC.P. Sm.
EN, Blab(iii)
Publicación: Sp. Lupinorum 34: 595. 1948.
Colección tipo: E.K. Balls 6735B
Hembarios: D S.
Nombre común: D esconocido.
Registro departamental: CU.
Regiones Ecológicas: MA; 3650-3700
SINAN PE: Sin registro.
Herbarios peruanos: Ninguno.

m.

Observaciones: Especie herbácea conocida solamente de la localidad tipo, proveniente de la cuenca del Yavero, de una planta recolectada en 1939. Esta localidad está ubicada adyacente al Parque Nacional Manu y por ello es probable que esté representada en esta área protegida.

\section{Lupinus mantaroensis C.P. Sm.}

$$
\text { EN, Blab(iii) }
$$

Publicación: Sp. Lupinorum 44: 754755. 1953.

Colección tipo: C. Ochoa 1004

Herbarios: D S; MOL!.

Nombre común: Desconocido.

Registro departamental: JU.

Regiones Ecológicas: MA; $3300 \mathrm{~m}$.

SINANPE: Sin registro.

Herbarios peruanos: MOL (isotipo).

Observaciones: Especie herbácea conocida solamente de la localidad tipo, en la cuenca del Mantaro. La especie es dudosa, pues el isotipo depositado en MOL se parece aL upinus lindleyanus, aunque con pelos más cortos.

\section{L upinus martinetianus (C.P. Sm.) C.P. Sm.}

NE

Publicación: Sp. Lupinorum 35: 623. 1948. Colección tipo: Martinet 347

Herbarios: P.

Nombre común: D esconocido.

Registro departamental: LI.

Regiones Ecológicas: MDE, MA; 2010 m.

SINAN PE: Sin registro.

Herbarios peruanos: Ninguno.

Observaciones: Esta especie herbácea es conocida para el norte de Lima, en las cuencas de los río Pativilca y Supe. Aparentemente no ha vuelto a ser recolectada desde 1939.

\section{Lupinus matucanicus Ulbr. var. matucanicus}

EN, Blab(iii)

Publicación:

Colección tipo: A. Weberbauer 5273

Herbarios: B, F.

Nombre común: Desconocido.

Registro departamental: LI.

Regiones Ecológicas: MDE; 1800- 2400 m.

SINAN PE: Sin registro.

Herbarios peruanos: Ninguno. 
Observaciones: Este taxón herbáceo es conocido solamente de la descripción original, de un ejemplar proveniente de la cuenca media del Rímac.

168. Lupinus matucanicus Ulbr. var. fistulosus C.P.Sm. CR, Blab(iii)

Publicación: Sp. Lupinorum 18: 273. 1941. Colección tipo: A. Mathews 921 Herbarios: E.

Nombre común: Desconocido. Registro departamental: LI.

Regiones Ecológicas: D ST; altitud desconocida.

SINAN PE: Sin registro.

Herbarios peruanos: Ninguno.

Observaciones: Este taxón es conocido solamente del material original, recolectado en el siglo XIX en la cuenca del Lurín, al sur de Lima. Junto con otras cuatro especies integra un grupo de taxones conocidos dela costa peruanay de muy pocos ejemplares de herbario.

\section{Lupinus misticola Ulbr.}

\section{EN, Blab(iii)}

Publicación: Notizbl. Bot. Gart. BerlinD ahlem 7(69): 453-454. 1920.

Colección tipo: A. Weberbauer 1423

Hembarios: B.

Nombre común: D esconocido.

Registro departamental: AR, MO

Regiones Ecológicas: PSH, PD ; 3500$4100 \mathrm{~m}$.

SINANPE: Sin registro.

Herbarios penuanos: CPUN (1).

Observaciones: Esta especie herbácea es conocida para la parte altoandina y Pacífica del sur del país, habiendo sido recolectada en por lo menos dos localidades. Al parecer, ha sido escasamente recolectada, apoyando la observación del escaso conocimiento botánico para esa parte del país.

\section{Lupinus mollendoensis Ulbr.}

\section{CR, Blab(iii)}

Publicación: Bot. Jahrb. Syst. 37(5): 547548. 1906.

Colección tipo: A. Weberbauer 1494

Herbarios: $\mathrm{B}$.

Nombre común: D esconocido.

Registro departamental: AR.

Regiones Ecológicas: D ST; 180- 750 m.

SINANPE: Sin registro.

Herbarios peruanos: USM (5).

Observaciones: Esta especie herbácea es conocida solamente para las lomas costeras de Arequipa. El rango geográfico de la distribución es potencialmente menora $100 \mathrm{~km}^{2}$. Esta es uno de los cuatro taxones de $\mathrm{L}$ upinus que forman parte de la flora de la costa peruana.

171. Lupinus munzianus C.P. Sm.

$$
\text { EN, Blab(iii) }
$$

Publicación: Sp. Lupinorum 9: 143- 144. 1940.

Colección tipo: C. Munz 15524

Herbarios: POM.

Nombre común: D esconocido.

Registro departamental: AR.

Regiones Ecológicas: MA; $2590 \mathrm{~m}$.

SINANPE: Sin registro.

\section{Hemarios peruanos: Ninguno.}

Observaciones: Especie herbácea o subarbustiva conocida solamente de la localidad tipo, ubicada en la cuenca del río Q uilca. Aparentemente no ha vuelto a ser recolectada desde 1939.

\section{Lupinus nehmadaeC.P. Sm.}

$$
\text { EN, Blab(iii) }
$$

Publicación: Sp. Lupinorum 35: 612. 1948.

Colección tipo: E. Nehmad 6056

Herbarios: D S.

Nombre común: Desconocido.

Registro departamental: AP.

Regiones Ecológicas: MA; $2930 \mathrm{~m}$.

SINANPE: Sin registro.

Herbarios peruanos: Ninguno.

Observaciones: Especie subarbustiva conocida solamente del material tipo, recolectado en la cuenca del Pampas.

\section{Lupinus neocotus C.P. Sm.}

\section{EN, B 1ab(iii)}

Publicación: Sp. Lupinorum 35: 612613. 1948.

Colección tipo: E. Nehmad 607

Herbarios: D S.

Nombre común: D esconocido.

Registro departamental: AP.

Regiones Ecológicas: MA; 2980 m.

SINAN PE: Sin registro.

Hembarios peruanos: Ninguno.

Observaciones: Especie subarbustiva conocida solamente del material tipo, recolectado en la cuenca del Pampas.

\section{Lupinus notabilis C.P. Sm.}

\section{EN, B 1ab(iii)}

Publicación: Sp. Lupinorum 16: 244. 1941.

Colección tipo: E.K. Balls 6899

Herbarios: US.

Nombre común: D esconocido.

Registro departamental: AP, CU.

Regiones Ecológicas: MA; 3597-3627

m.

SINAN PE: Sin registro.

Hembarios peruanos: Ninguno.

Observaciones: Especie arbustiva conocida solamente de la colección tipo y una adicional recolectada en Cusco.

\section{L upinus ochoanus C.P. Sm.}

$$
\text { EN, B lab(iii) }
$$

Publicación: Sp. Lupinorum 44: 767. 1953.

Colección tipo: C. O choa 724

Hemarios: D S; MOL!

Nombre común: D esconocido.

Registro departamental: JU.

Regiones Ecológicas: MA; $3450 \mathrm{~m}$.

SINANPE: Sin registro.

Herbarios penuanos: MOL (isotipo).

Observaciones: Especie arbustiva conocida solamente del material tipo, recolectado en la cuenca del Perené. 
176. Lupinus oquendoanus C.P. Sm.

\section{DD}

Publicación: Sp. Lupinorum 17: 265.

1941.

Colección tipo: O quendo 9

Hemarios: $\mathrm{K}$.

Nombre común: D esconocido.

Registro departamental: PU.

Regiones Ecológicas: Sin datos; altitud desconocida.

SINAN PE: Sin registro.

Herbarios peruanos: Ninguno.

Observaciones: Esta especie herbácea y perenne es conocida solamente de la colección tipo, careciéndose de datos de localidad y hábitat específicos.

\section{Lupinus otuzcoensis C.P. Sm.}

EN, B lab(iii)

Publicación: Sp. Lupinorum 44: 755. 1953.

Colección tipo: C. O choa 1441

Herbarios: DS.

Nombre común: D esconocido.

Registro departamental: LL.

Regiones Ecológicas: MA; 3100 m.

SINAN PE: Sin registro.

Herbarios peruanos: Ninguno.

Observaciones: Especie herbácea conocida solamente del material tipo, recolectado en la cuenca del Chicama en lavertiente del Pacífico. Aparentemente no ha vuelto a ser recolectada desde 1952.

\section{Lupinus pachitensisC.P. Sm.}

\section{EN, B lab(iii)}

Publicación: Sp. Lupinorum 44: 764765. 1953.

Colección tipo: C. Ochoa 1106

Herbarios: D S; MOL!.

Nombre común: D esconocido.

Registro departamental: HU.

Regiones Ecológicas: MA; 3000 m.

SINAN PE: Sin registro.

Herbarios peruanos: MOL (isotipo).

Observaciones: Especie herbácea o subarbustiva conocida solamente del material tipo, recolectado en la cuenca del Huallaga.

\section{Lupinus parumeensis C.P. Sm.}

\section{VU, B lab(iii)}

Publicación: Sp. Lupinorum 31: 540541. 1945.

Colección tipo: C. Vargas C. 2348

Herbarios: DS.

Nombre común: D esconocido.

Registro departamental: CU, TA.

Regiones Ecológicas: MA, PSH; 3380$4325 \mathrm{~m}$.

SINAN PE: Sin registro.

Herbarios peruanos: USM (4).

Observaciones: Especie herbácea conocida solamente para el sur del país, en las cuencas del Apurímac, Urubamba y Sama.
180. L upinus paucartambensis C.P. Sm.

$$
\text { EN, Blab(iii) }
$$

Publicación: Sp. Lupinorum 31: 542. 1945.

Colección tipo: C. Vargas C. 4315

Herbarios: D S.

Nombre común: D esconocido.

Registro departamental: CU, PA.

Regiones Ecológicas: MA, BPM; 3200$3500 \mathrm{~m}$.

SINANPE: Sin registro.

Herbarios peruanos: Ninguno.

Observaciones: Especie arbustiva conocida paralas regiones centro y sur del país, en las cuencas del Yavero y Alto Huallaga. El ejemplar tipo fue recolectado muy cerca del límite occidental del Parque Nacional Manu y es probable que esté representada allí.

\section{Lupinus penblandus C.P. Sm.}

\section{DD}

Publicación: Sp. Lupinorum 11: 169. 1940.

Colección tipo: R.W. Pearce s.n.

Hemarios: $\mathrm{K}$.

Nombre común: D esconocido.

Registro departamental: HV.

Regiones Ecológicas: Sin datos; altitud desconocida.

SINAN PE: Sin registro.

Herbarios peruanos: Ninguno.

Observaciones: Especie arbustiva conocida solamente de la descripción original, cuya localidad no se precisa con claridad; probablemente se trate de Huaytará.

\section{Lupinus penuvianus Ulbr.}

\section{NT}

Publicación: Bot. Jahrb. Syst. 37(5): 544545. 1906.

Colección tipo: A. Weberbauer 3980

Hemanios: $B$.

Nombre común: D esconocido.

Registro departamental: AM, AP, AY, CA, CU, JU, PA.

Regiones Ecológicas: MA, PSH, PAR; $3300-4100 \mathrm{~m}$.

SINAN PE: Sin registro.

Herbarios peruanos: HAO (1).

Observaciones: Especie herbácea conocida de varias localidades a lo largo del país. Probablemente los incendios intencionales y pastoreo afecten a esta especie.

\section{Lupinus pickeningii A. Gray}

$$
\text { EN, Blab(iii) }
$$

Publicación: U.S. Expl. Exped., Phan. 1: 392. 1854.

Colección tipo: C. Wilkes, Exped. Expl. US. s.n.

Herbarios: US

Nombre común: D esconocido.

Registro departamental: LI.

Regiones Ecológicas: PSH; altitud desconocida.

SINANPE: Sin registro.

Herbarios peruanos: Ninguno. 
Observaciones: Esta especie subarbustiva es conocida solamente de la vertiente del Pacífico, de las cuencas del Chillón y del Rímac. Probablemente se encuentre distribuida para la sierra central del país. A parentemente no ha vuelto a ser recolectada desde la década de 1920.

\section{Lupinus pinguis Ulbr.}

\section{CR, Blab(iii)}

Publicación: Notizbl. Bot. Gart. BerlinDahlem 7(69): 452-453. 1920.

Colección tipo: A. Weberbauer 5458

Hemarios: $B$.

Nombre común: D esconocido.

Registro departamental: HV.

Regiones Ecológicas: AA; 4500-4600 m.

SINANPE: Sin registro.

Herbarios peruanos: Ninguno.

Observaciones: Esta especie herbácea es conocida solamente del material tipo, proveniente de la cuenca del Apacheta, un tributario del río Pampas. Aparentemente no ha vuelto a ser recolectada desde 1910, confirmando el reconocimiento de esa parte del país como una zona con poco estudio botánico.

\section{Lupinus pipersmithianus J.F. Macbr.}

\section{CR, Blab(iii)}

Publicación: Field Mus. Nat. Hist., Bot. Ser. 13(3/ 1): 496. 1943

Colección tipo: T. G oodspeed 10594

Herbarios: UC.

Nombre común: D esconocido.

Registro departamental: AP.

Regiones Ecológicas: MA; 3100 m.

SINANPE: Sin registro.

Hembarios peruanos: Ninguno.

Observaciones: Especie arbustiva conocida solamente para la sierra de Abancay, en la cuenca del Apurímac. Probablemente esté representada en el Santuario Nacional de Ampay. Aparentemente no ha vuelto a ser recolectada desde 1939. Amenazas a sus poblaciones podrían estar asociadas a las actividades agrícolas como quemas y pastoreo intensivo.

\section{L upinus pisacensis C.P. Sm.}

$$
\text { EN, Blab(iii) }
$$

Publicación: Sp. Lupinorum 33: 589. 1948.

Colección tipo: C. Vargas C. 5209

Herbarios: D S.

Nombre común: D esconocido.

Registro departamental: CU.

Regiones Ecológicas: PSH; 3900 m.

SINANPE: Sin registro.

Herbarios peruanos: Ninguno.

Observaciones: Especie subarbustiva conocida solamente de la parte alta de Pisac, en la cuenca del Urubamba. La colección tipo fue realizada en 1945.
187. Lupinus piurensis C.P. Sm.

$$
\text { CR, Blab(iii) }
$$

Publicación: Sp. Lupinorum 44: 768. 1953.

Colección tipo: C. O choa 1799

Hemarios: D S; MOL!

Nombre común: Desconocido.

Registro departamental: PI.

Regiones Ecológicas: MA; 2000 m.

SINAN PE: Sin registro.

Herbarios penuanos: MOL (isotipo).

Observaciones: Especie herbácea conocida solamente de la colección tipo, proveniente de la cuenca del Piura-Cascajal. Esta especie probablemente crezca en una zona ecotonal de pajonales a matorrales o bosques montanos. Esta zona está sometida a deforestación.

\section{Lupinus platyptenus C.P. Sm.}

\section{EN, Blab(iii)}

Publicación: Sp. Lupinorum 34: 599. 1948.

Colección tipo: C. Vargas C. 5993

Herbarios: D S.

Nombre común: Desconocido.

Registro departamental: CU.

Regiones Ecológicas: BMHM; $2500 \mathrm{~m}$.

SINANPE: Sin registro.

Hembarios peruanos: Ninguno.

Observaciones: Especie subarbustiva conocida sólo de la colección tipo, en el valle del Urubamba. Es probable su presencia dentro del Santuario Histórico de Machu Picchu. Aparentemente no havuelto a ser recolectada desde 1946.

\section{Lupinus preaealtus C.P. Sm.}

$$
\text { EN, B1ab(iii) }
$$

Publicación: Sp. Lupinorum 11: 163164. 1940.

Colección tipo: J.F. Macbride \& W. Featherstone 2144

Henbarios: F, US.

Nombre común: D esconocido.

Registro departamental: CU, HU, LI.

Regiones Ecológicas: MA; 3100—3500 m.

SINAN PE: Sin registro.

Herbarios peruanos: Ninguno.

Observaciones: Especie arbustiva conocida para la zona centro y sur del país, en las cuencas del Chillón, Huallaga y Urubamba. Aparentemente, las colecciones de herbario conocidas fueron recolectadas hasta mediados de los 1920. Los ambientes de donde se conoce están afectados por los incendios intencionales.

\section{Lupinus praestabilis C.P. Sm.}

\section{CR, B lab(iii)}

Publicación: Sp. Lupinorum 33: 587588. 1948.

Colección tipo: C. Vargas C. 5052

Herbarios: D S.

Nombre común: D esconocido.

Registro departamental: CU.

Regiones Ecológicas: MA; $3500 \mathrm{~m}$.

SINAN PE: Sin registro.

Herbarios peruanos: Ninguno. 
Observaciones: Especie subarbustiva conocida sólo de la colección tipo, proveniente de la cuenca del Urubamba. Aparentemente no ha vuelto a ser recolectada desde la década de 1940.

\section{Lupinus praetermissus C.P. Sm.}

$$
\text { EN, B lab(iii) }
$$

Publicación: Sp. Lupinorum 12: 183. 1940.

Colección tipo: A. Weberbauer 5480

Herbarios: $B$.

Nombre común: D esconocido.

Registro departamental: AY, CU.

Regiones Ecológicas: MA; altitud desconocida.

SINAN PE: Sin registro.

Herbarios peruanos: Ninguno.

Observaciones: Esta especie arbustiva es conocida para el sur y centro del país, en las cuencas del Mantaro y Urubamba. Al igual que otras especies en el género, se conoce de ejemplares de herbario recolectados a inicios del siglo XX.

\section{Lupinus proculaustrinus C.P. Sm.}

\section{EN, B 1ab(iii)}

Publicación: Sp. Lupinorum 34: 607608. 1948.

Colección tipo: R.D. Metcalf 30409

Herbarios: MO, US.

Nombre común: D esconocido.

Registro departamental: TA.

Regiones Ecológicas: MA; $2500 \mathrm{~m}$.

SINANPE: Sin registro.

Herbarios peruanos: Ninguno.

Observaciones: Esta especie arbustiva es conocida solamente de la colección tipo, proveniente de las alturas del Tarata, en la cuenca del Sama.

\section{Lupinus pucapucensis C.P. Sm.}

\section{EN, B 1ab(iii)}

Publicación: Sp. Lupinorum 34: 593. 1948.

Colección tipo: C. Vargas C. 5567

Herbarios: DS.

Nombre común: D esconocido.

Registro departamental: AP, CU.

Regiones Ecológicas: BPM, MA; 2600$3600 \mathrm{~m}$.

SINANPE: Sin registro.

Herbarios peruanos: Ninguno.

Observaciones: Especie subarbustiva conocida para el sur del país, en las cuencas del Yavero y Apurímac. Probablemente esté representada en el Parque Nacional Manu, debido a que la localidad original está ubicada en los límites occidentales de esa área protegida.

\section{Lupinus puyupatensis C.P. Sm.}

\section{EN, B lab(iii)}

Publicación: Sp. Lupinorum 31: 538539. 1945.

Colección tipo: C. Vargas C. 2715

Hembarios: DS.

Nombre común: D esconocido.

Registro departamental: CU.

Regiones Ecológicas: MA; 2600-3000 m.

SINANPE: Sin registro.

Hembarios peruanos: Ninguno.
Observaciones: Especie herbácea conocida solamente de la colección tipo, proveniente de la cuenca del Urubamba. Probablemente estérepresentada en el Santuario Histórico de Machu Picchu.

195. Lupinus quellomayus C.P. Sm.

$$
\text { EN, Blab(iii) }
$$

Publicación: Sp. Lupinorum 33: 592. 1948.

Colección tipo: C. Vargas C. 4449

Herbarios: D S.

Nombre común: D esconocido.

Registro departamental: CU.

Regiones Ecológicas: PSH; 3700 m.

SINANPE: Sin registro.

Herbarios peruanos: Ninguno.

Observaciones: Especie herbácea conocida solamente de la colección tipo, proveniente de la cuenca del Urubamba. Esta es una de trece especies endémicas del género conocidas de esta cuenca y cuyas poblaciones están naturalmente fragmentadas al ocupar una variedad de ambientes.

\section{Lupinus romasanus Ulbr.}

$$
\text { VU, Blab(iii), D2 }
$$

Publicación: Bot. Jahrb. Syst. 37(5): 546547. 1906.

Colección tipo: A. Weberbauer 3206

Hembarios: $F$

Nombre común: D esconocido.

Registro departamental: AN, CA, LL.

Regiones Ecológicas: MA, PSH; 2100$3750 \mathrm{~m}$.

SINANPE: Sin registro.

Herbarios penuanos: MOL (3).

Observaciones: Esta especie herbácea es conocida para la vertiente Pacífica en el norte del país, en las cuencas del Santa, Jequetepeque y Moche. Los ambientes de esta especieno reciben protección oficial. Probablemente la expansión agrícola e incendios intencionales afecten las poblaciones de esta especie.

\section{Lupinus sandiensis C.P. Sm.}

$$
\text { CR, Blab(iii) }
$$

Publicación: Sp. Lupinorum 31: 539. 1945.

Colección tipo: C. Vargas C. 1925

Herbarios: D S.

Nombre común: D esconocido.

Registro departamental: PU.

Regiones Ecológicas: MA, BMHM; 2800 $\mathrm{m}$.

SINAN PE: Sin registro.

Herbarios peruanos: Ninguno.

Observaciones: Esta especie herbácea es conocida solamente de la localidad tipo, ubicada al noroeste de Sandia, en la cuenca del Inambari. Esta localidad ocupa una zona ecotonal de bosque montano y pajonales mesoandinos debido a las características más xéricas de ese valle (Weberbauer, 1945). Probablementelos incendios intencionales y pastoreo constituyan las actividades que afecten a esta especie. 


\section{L upinus saxatilis Ulbr.}

$$
\text { CR, Blab(iii) }
$$

Publicación: Bot. Jahrb. Syst. 37(5): 548. 1906. Colección tipo: A. Weberbauer 1386

Herbarios: B; USM!.

Nombre común: D esconocido.

Registro departamental: AR.

Regiones Ecológicas: AA, PSH; 3800$4500 \mathrm{~m}$

SINANPE: Sin registro.

Hembarios penuanos: USM (isotipo).

Observaciones: Estaespecie herbáceao subarbustiva hasido registrada en Arequipa, en la parte alta de la cuenca del Quilca. Un ejemplar adicional procedente de la cuenca del Jequetepeque es reconocido como esta especie, pero no pudo verificarse su identificación. Esta localidad dista más de $1000 \mathrm{~km}$ en línea recta de la localidad original. Aquí se reconoce esta especie con distribución restringida al sur del país. La localidad original tiene caracteństicas xéricas.

\section{Lupinus semiprostratus C.P. Sm.}

\section{EN, Blab(iii)}

Publicación: Sp. Lupinorum 16: 244245. 1941.

Colección tipo: E.K. Balls 6735

Herbarios: MO, NY, US.

Nombre común: D esconocido.

Registro departamental: CU, LL.

Regiones Ecológicas: PSH, PAR; 3660$4000 \mathrm{~m}$.

SINANPE: Sin registro.

Herbarios penuanos: HUT (1).

Observaciones: Esta especie arbustiva es conocida oniginalmente de la cuenca del Alto Madre de Dios. Una colección adicional proveniente de la cuenca del Marañón ha sido reconocida como esta especie. Estas localidades distan entre ellas por más de $1000 \mathrm{~km}$ en línea recta.

\section{Lupinus semperflorens Hartw. var. peruensis C.P. Sm.}

$$
\text { CR, B1ab(iii) }
$$

Publicación: Sp. Lupinorum 44: 768. 1953.

Colección tipo: C. O choa 1793

Herbarios: US.

Nombre común: D esconocido.

Registro departamental: PI.

Regiones Ecológicas: MDE, MA; $2000 \mathrm{~m}$.

SINANPE: Sin registro.

Herbarios peruanos: Ninguno.

Observaciones: Arbusto conocido solamente de la colección tipo, proveniente del bosque de Cuyas, en la cuenca del Chira en la vertiente occidental. Este bosque está severamente fragmentado por la expansión agrícola y deforestación.

201. Lupinus seniceolodix C.P. Sm.

$$
\text { EN, Blab(iii) }
$$

Publicación: Sp. Lupinorum 17: 266. 1941.

Colección tipo: P. Ledig 19

Herbarios: US.

Nombre común: D esconocido.

Registro departamental: JU.

Regiones Ecológicas: PSH; $4000 \mathrm{~m}$.

SINANPE: Sin registro.

Herbarios peruanos: Ninguno.
Observaciones: Esta especie arbustiva es conocida solamente de la colección tipo, proveniente de la parte alta de la cuenca del Mantaro, una zona escasamente herborizada.

\section{Lupinus soukupianus C.P. Sm. ex J.F. Macbr.}

$$
\text { CR, Blab(iii) }
$$

Publicación: Revista Univ. (Cuzco) 33(87): 154. 1945.

Colección tipo: J. Soukup 1938

Hembarios: US.

Nombre común: D esconocido.

Registro departamental: LI.

Regiones Ecológicas: PSH; altitud desconocida.

SINANPE: Sin registro.

Herbarios peruanos: Ninguno.

Observaciones: Esta especie es conocida solamente de la colección original, recolectada en la cuenca alta del Santa Eulalia, un tributario del Rímac. Aparentemente no ha vuelto a ser recolectada desde la década de 1940. Los ambientes naturales en la cuenca del Rímac, incluyendo sus tributarios, han sido modificados desde esos años ya sea por actividades agropecuarias como por las mineras y la construcción de carreteras, entre otras.

\section{L upinus staffordiae C.P. Sm.}

\section{DD}

Publicación: Sp. Lupinorum 11: 168. 1940.

Colección tipo: D. Stafford 11

Henbarios: $\mathrm{K}$.

Nombre común: D esconocido.

Registro departamental: CU.

Regiones Ecológicas: Sin datos; altitud desconocida.

SINANPE: Sin registro.

Herbarios peruanos: Ninguno.

Observaciones: Esta especie es conocida solamente de la colección original en la cuenca del Vilcanota, aunque se carece de los datos exactos de localidad y hábitat. Aparentemente no ha vuelto a ser recolectada desde la década de 1930.

\section{Lupinus storkianus C.P. Sm.}

\section{DD}

Publicación: Sp. Lupinorum 34: 606. 1948. Colección tipo: H.E. Stork \& O.B. Horton 10201

Hemarios: UC.

Nombre común: D esconocido.

Registro departamental: CA.

Regiones Ecológicas: Sin datos; altitud desconocida.

SINANPE: Sin registro.

Henbarios peruanos: Ninguno.

Observaciones: Esta especie es conocida solamente de la colección original, aunque se carece de los datos exactos de localidad y hábitat. 


\section{Lupinus surcoensis C.P. Sm.}

$$
\text { EN, B1ab(iii) }
$$

Publicación: Sp. Lupinorum 44: 766. 1953.

Colección tipo: C. O choa 1161

Herbarios: DS; MOL!

Nombre común: D esconocido.

Registro departamental: LI.

Regiones Ecológicas: MA; 2000 m.

SINAN PE: Sin registro.

Herbarios penuanos: MOL (isotipo).

Observaciones: Esta especie arbustiva es conocida solamente de la localidad tipo, situada en la cuenca media del Rímac. El isotipo depositado en MOL se parece a L upinus ballianus, por lo que podría tratarse de la misma especie. Por el momento se acepta el estatus de L upinus surcoensis, pero se requiere estudios que evalúen su situación taxonómica.

\section{Lupinus syriggedes C.P. Sm.}

\section{EN, B 1ab(iii)}

Publicación: Sp. Lupinorum 18: 283284. 1941

Colección tipo: E.P. Killip \& A.C. Smith 21653

Herbarios: NY, US.

Nombre común: Desconocido.

Registro departamental: LI.

Regiones Ecológicas: MA; 3000- 3500 m.

SINAN PE: Sin registro.

Herbarios peruanos: Ninguno.

Observaciones: Esta especie arbustiva es conocida solamente de la localidad tipo, situada en la cuenca alta del Rímac. A parentemente no ha vuelto a ser recolectada desde 1929. La minería, pastoreo e incendios intencionales podrían afectar a esta especie.

\section{Lupinus tarmaensis C.P. Sm.}

\section{EN, B lab(iii)}

Publicación: Sp. Lupinorum 44: 767768. 1953.

Colección tipo: C. 0 choa 71

Herbarios: D S.

Nombre común: D esconocido.

Registro departamental: JU.

Regiones Ecológicas: BMHM; $2200 \mathrm{~m}$.

SINANPE: Sin registro.

Herbarios peruanos: Ninguno.

Observaciones: Esta especie herbácea es conocida solamente del material tipo, proveniente del valle de Chanchamayo. El isotipo depositado en MOL es muy parecido a L upinus ellsworthianus, L. carpapaticus, L. disjunctus y L. albertsmithianus, todos recolectados entre Carpapata y Huacapistana.

208. Lupinus tayacajensis C.P. Sm.

$$
\text { EN, B 1ab(iii) }
$$

Publicación: Sp. Lupinorum 44: 762. 1953.

Colección tipo: C. O choa 974

Herbarios: DS.

Nombre común: D esconocido.

Registro departamental: HV.

Regiones Ecológicas: MA; 1900— 2200 m.

SINAN PE: Sin registro.

Herbarios peruanos: Ninguno.
Observaciones: Esta especie herbácea es conocida solamente del material tipo, encontrado en Colcabamba, cuenca del Mantaro. Aparentemente no ha sido recolectada desde 1951.

\section{Lupinus tetracercophorus C.P. Sm.}

EN, Blab(iii)

Publicación: Sp. Lupinorum 35: 611. 1948.

Colección tipo: C. Vargas C. 6636

Herbarios: D S.

Nombre común: D esconocido.

Registro departamental: AP.

Regiones Ecológicas: MA; 3300-3600 m. SINANPE: Sin registro.

Herbarios peruanos: Ninguno.

Observaciones: Esta especie subarbustiva es conocida sólo del material tipo, proveniente de Abancay, en la cuenca del Apurímac. Esta localidad está afectada por el pastoreo intensivo y la expansión agrícola.

\section{L upinus toratensis C.P. Sm.}

$$
\text { CR, Blab(iii) }
$$

Publicación: Sp. Lupinorum 12: 179. 1940.

Colección tipo: A. Weberbauer 7467

Herbarios: US.

Nombre común: D esconocido.

Registro departamental: MO.

Regiones Ecológicas: MA; 3200-3300 m.

SINANPE: Sin registro.

Herbarios peruanos: Ninguno.

Observaciones: Especie arbustiva conocida solamente del material tipo, recolectado en Cuajone, cuenca del Ilo-Moquegua. Aparentemente no ha vuelto a ser recolectada desde 1925. Las actividades mineras podrían afectar a esta especie.

\section{Lupinus urcoensis C.P. Sm.}

EN, Blab(iii)

Publicación: Sp. Lupinorum 31: 543. 1945.

Colección tipo: C. Vargas C. 692

Henbarios: DS.

Nombre común: D esconocido.

Registro departamental: CU.

Regiones Ecológicas: MA; 2950 m.

SINAN PE: Sin registro.

Herbarios peruanos: USM (1).

Observaciones: Especie herbácea o arbustiva conocida solamente para el Cusco, en la cuenca del Urubamba. La recolecta botánica más reciente data de 1987. La poca representación de esta especie se deba en general a lo poco que se herboriza el género L upinus, dada la escasez de información taxonómica y de material de herbario para comparación.

\section{L upinus urubambensis C.P. Sm.}

\section{EN, Blab(iii)}

Publicación: Sp. Lupinorum 16: 245246. 1941.

Colección tipo: E.K. Balls 6805

Henbarios: US.

Nombre común: D esconocido.

Registro departamental: CU.

Regiones Ecológicas: BMHM; $1650 \mathrm{~m}$.

SINANPE: SHMP

Herbarios peruanos: Ninguno. 
Observaciones: Especie arbustiva conocida solamente para la región de Machu Picchu, en el valle del Urubamba. Aparentemente no ha vuelto a ser recolectada desde 1939. Los incendios intencionales podrían afectar a esta especie.

\section{Lupinus vargasianusC.P. Sm.}

$$
\text { EN, Blab(iii) }
$$

Publicación: Sp. Lupinorum 31: 543544. 1945.

Colección tipo: C. Vargas C. 4130

Herbarios: D S.

Nombre común: D esconocido.

Registro departamental: CU.

Regiones Ecológicas: BMHM; $2650 \mathrm{~m}$.

SINANPE: SHMP

Hembarios peruanos: Ninguno.

Observaciones: Especie herbácea conocida solamente para la región de Machu Picchu, en el valle del Urubamba. Esta especie no ha vuelto a ser recolectada desde 1944. Los incendios intencionales podrían afectar a esta especie.

\section{Lupinus velillensis C.P. Sm.}

$$
\text { EN, Blab(iii) }
$$

Publicación: Sp. Lupinorum 33: 591. 1948.

Colección tipo: C. Vargas C. 6551

Herbarios: D S.

Nombre común: D esconocido.

Registro departamental: CU.

Regiones Ecológicas: MA; 3760 m.

SINAN PE: Sin registro.

Herbarios peruanos: Ninguno.

Observaciones: Especie herbácea conocida solamente del material tipo, proveniente de la cuenca del A purímac. Aparentemente no ha vuelto a ser recolectada desde 1947. La localidad original está ubicada en una zona con escaso estudio botánico.

\section{Lupinus vilcabambensis C.P. Sm.}

$$
\text { EN, Blab(iii) }
$$

Publicación: Sp. Lupinorum 31: 539540. 1945.

Colección tipo: C. Vargas C. 3852

Herbarios: DS, MO.

Nombre común: D esconocido.

Registro departamental: CU.

Regiones Ecológicas: MA; $2500 \mathrm{~m}$.

SINAN PE: Sin registro.

Hembarios peruanos: Ninguno.

Observaciones: Esta especie herbácea es conocida solamente del material tipo, proveniente de Calca, en la cuenca del Urubamba.

\section{Lupinus visoensis J.F. Macbr.}

$$
\text { CR, Blab(iii) }
$$

Publicación: Publ. Field Columbian Mus., Bot. Ser. 8(2): 97. 1930.

Colección tipo: J.F. Macbride \& W. Featherstone 596

Herbarios: F.

Nombre común: D esconocido.

Registro departamental: LI.

Regiones Ecológicas: MA; $2745 \mathrm{~m}$.

SINAN PE: Sin registro.

Herbarios peruanos: Ninguno.
Observaciones: Especie arbustiva conocida sólo del material tipo, encontrado en Huarochirí, cuenca media del Rímac a inicios de la década de 1920. Losincendios intencionales asociados a la agricultura y la presencia en las cercanías de la Carretera Central podrían ser asuntos problemáticos para esta especie.

\section{L upinus volubilis C.P. Sm.}

\section{CR, B lab(iii)}

Publicación: Sp. Lupinorum 34: 596. 1948.

Colección tipo: C. Vargas C. 6645

Herbarios: DS.

Nombre común: D esconocido.

Registro departamental: CU.

Regiones Ecológicas: BPM; 3400 m.

SINAN PE: Sin registro.

Herbarios peruanos: Ninguno.

Observaciones: Especie herbácea conocida solamente del material tipo, recolectado en 1947 y proveniente de los alrededores de Marcapata, en la cuenca del Inambari. Los ambientes en la localidad original están afectados por la expansión agnícola y actividades asociadas.

\section{L upinus weberbauen Ulbr. var. weberbauen}

$$
\text { VU, Bla }
$$

Publicación:

Colección tipo: A. Weberbauer 3264

Herbarios: B; MOL!.

Nombre común: D esconocido.

Registro departamental: AN, LL. Regiones Ecológicas: PSH, AA; 3900$4800 \mathrm{~m}$.

SINANPE: PNH

Henbarios peruanos: MOL (isotipo+1).

Observaciones: Este taxón herbáceo es conocido de las partes altoandinas de Ancash y La Libertad. Poblaciones extensas están presentes en el Parque Nacional Huascarán.

\section{Lupinus weberbaueni Ulbr. var, ochoanii C.P. Sm.}

$$
\text { EN, Bla }
$$

Publicación: Sp. Lupinorum 44: 753754. 1953.

Colección tipo: C. O choa 992

Hemarios: D S; MOL!

Nombre común: Desconocido.

Registro departamental: JU.

Regiones Ecológicas: MA; 3700 m.

SINAN PE: Sin registro.

Herbarios peruanos: MOL (isotipo).

Observaciones: Esta variedad herbácea o subarbustiva es conocida sólo del material tipo, proveniente de la parte alta de la cuenca del Mantaro. Aparentemente no ha vuelto a ser recolectada desde 1951.

\section{Lupinus wilkesianus C.P. Sm.}

\section{EN, B 1ab(iii)}

Publicación: Sp. Lupinorum 10: 156. 1940. Colección tipo: C. Wilkes, Exped. Expl. US. s.n.

Hembarios: US.

Nombre común: D esconocido.

Registro departamental: LI.

Regiones Ecológicas: MA; 3200-3500 m.

SINANPE: Sin registro.

Hembarios peruanos: Ninguno. 
Observaciones: Especie arbustiva restringida aparentemente a la cuenca del Chillón. Macbride (1943) citando a Smith (1940) comentó la duda sobre la presencia de esta especie en Cusco.

221. Lupinus williamlobbii C.P. Sm.

\section{CR, Bla}

Publicación: Sp. Lupinorum 33: 585. 1948 Colección tipo: W. Lobb s.n.

Herbarios: K.

Nombre común: D esconocido.

Registro departamental: CU.

Regiones Ecológicas: MA; altitud desconocida.

SINANPE: Sin registro.

Herbarios peruanos: Ninguno.

Observaciones: Especie subarbustiva conocida sólo del material tipo, encontrada en inmediaciones de la ciudad de Cusco, cuenca del Vilcanota. Probablemente el crecimiento urbano podría explicar que aparentemente no ha vuelto a ser recolectada en esta localidad.

\section{Lupinus xanthophyllus C.P. Sm.}

\section{EN, B 1ab(iii)}

Publicación: Sp. Lupinorum 36: 626. 1948

Colección tipo: Y. Mexia 4157

Herbarios: UC.

Nombre común: D esconocido.

Registro departamental: HU.

Regiones Ecológicas: BMHM; 2300 m.

SINANPE: Sin registro.

Herbarios peruanos: Ninguno.

Observaciones: Especie subarbustiva conocida sólo del material tipo, encontrada en inmediaciones de Huánuco, en la cuenca del Huallaga. Aparentemente no ha vuelto a ser recolectada desde 1935.

\section{Lupinus yanahuancensis C.P. Sm.}

\section{EN, B 1ab(iii)}

Publicación: Sp. Lupinorum 36: 628629. 1948.

Colección tipo: J.F. Macbride \& W. Featherstone 1291b

Herbarios: UC.

Nombre común: D esconocido.

Registro departamental: PA.

Regiones Ecológicas: MA, PSH; 3000$3500 \mathrm{~m}$.

SINAN PE: Sin registro.

Herbarios peruanos: Ninguno.

Observaciones: Esta especie es conocida solamente del tipo, recolectado hace más de 80 años, en la parte occidental de Pasco, cuenca del Alto Huallaga. Esta zona ha sido escasamente herborizada durante los últimos 50 años.

\section{Lupinus yarushensis C.P. Sm.}

\section{EN, B lab(iii)}

Publicación: Sp. Lupinorum 44: 760. 1953.

Colección tipo: C. Ochoa 1113

Herbarios: DS.

Nombre común: D esconocido.

Registro departamental: PA.

Regiones Ecológicas: PSH; $4000 \mathrm{~m}$.

SINAN PE: Sin registro.

Herbarios peruanos: Ninguno.
Observaciones: Esta especie herbácea o subarbustiva es conocida solamente de la localidad tipo, situada en la cuenca del Alto Huallaga. Esta zona requiere de más estudios botánicos. Aparentemente no ha vuelto a ser recolectada desde 1951.

\section{L upinus yaulyensis C.P. Sm.}

$$
\text { CR, Blab(iii) }
$$

Publicación: Sp. Lupinorum 17: 264265. 1941.

Colección tipo: A. Weberbauer 351

Herbarios: $B$.

Nombre común: D esconocido.

Registro departamental: JU.

Regiones Ecológicas: PSH; altitud desconocida.

SINAN PE: Sin registro.

Herbarios peruanos: Ninguno.

Observaciones: Esta especie herbácea es conocida solamente de la colección original, proveniente de la parte occidental de Junín, en la cuenca alta del Rímac, recolectada hace más de 100 años.

226. Lupinus ynesiae C.P. Sm.

$$
\text { EN, Blab(iii) }
$$

Publicación: Sp. Lupinorum 18: 281282. 1941.

Colección tipo: Y. Mexia 8076

Hemarios: D S, MO, UC, US.

Nombre común: D esconocido.

Registro departamental: $\mathrm{CU}$.

Regiones Ecológicas: BMHM; $2200 \mathrm{~m}$.

SINANPE: SHMP

Herbarios peruanos: Ninguno.

Observaciones: Esta especie herbácea es conocida solamente del material tipo, recolectado en Cusco, en la cuenca del Urubamba. A parentementeno ha vuelto a ser recolectada desde 1936. Amenazas a sus poblaciones provienen de los incendios intencionales.

\section{Machaenium cuzcoense Rudd}

$$
\text { CR, Blab(iii) }
$$

Publicación: Phytologia 25(6): 403. 1973. Colección tipo: R. Chávez 423 Herbarios: $F$.

Nombre común: D esconocido.

Registro departamental: CU.

Regiones Ecológicas: BMHP; $1300 \mathrm{~m}$.

SINAN PE: Sin registro.

Herbarios peruanos: Ninguno.

Observaciones: Esta especie se conoce solamente de una localidad en la parte oriental de Cusco. Podría ser una especialista de ambientes abiertos o representar remanente de una vegetación más densa. La localidad original no se encuentra protegida por el Estado. Esta localidad se ubica en una zona con alta tasa de deforestación, que podría poner en riesgo las poblaciones de esta especie.

228. Machaerium floribundum Benth. var. hypargyreum (Harms) Rudd

Publicación: Phytologia 24(2): 122. 1972.

Colección tipo: G. Tessmann 4549

Herbarios: B, G.

Nombre común: D esconocido.

Registro departamental: AM.

Regiones Ecológicas: BHA; 270-330 m.

SINAN PE: Sin registro.

Herbarios peruanos: Ninguno. 
Observaciones: Este taxón fue considerado por Brako \& Zarucchi (1993) como un endemismo; sin embargo, no ha sido posible evaluarlo, ni asignarle una categoría.

\section{Machaenium huanucoense Rudd}

Publicación: Phytologia 25(6): 401. 1973.

Colección tipo: J. Schunke V. 5895

Herbarios: F, UCLA, US

Nombre común: Huasca barbasco.

Registro departamental: HU.

Regiones Ecológicas: BMHP; $672 \mathrm{~m}$.

SINANPE: Sin registro.

Herbarios peruanos: Ninguno.

Observaciones: Liana conocida de la cuenca del Huallaga. Esta especie fue descrita de una planta recolectada en 1962. No ha sido posible evaluarla, ni asignarle una categoría.

230. Machaenium peruvianum J.F. Macbr.

Publicación: Field Mus. Nat. Hist., Bot. Ser. 13(3/ 1): 284. 1943.

Colección tipo: L. Williams 3441

Herbarios: $F$.

Nombre común: D esconocido.

Registro departamental: SM.

Regiones Ecológicas: BHA; $350 \mathrm{~m}$.

SINAN PE: Sin registro.

Herbarios peruanos: Ninguno.

Observaciones: Este taxón fue considerado por Brako \& Zarucchi (1993) como un endemismo; sin embargo, no ha sido posible evaluarlo, ni asignarle una categoría.

\section{Macrolobium klugii R.S. Cowan}

Publicación: Mem. New York Bot. Gard. 8(4): 309-310, f. 8. 1953.

Colección tipo: G. Klug 1353

Hemarios: $F$, US

Nombre común: D esconocido.

Registro departamental: LO.

Regiones Ecológicas: BHA; $100 \mathrm{~m}$.

SINANPE: Sin registro.

Herbarios peruanos: Ninguno.

Observaciones: Especie arbórea, aparentemente, conocida de la localidad tipo, en los alrededores de Iquitos. El ejemplar tipo fue recolectado en 1930. No ha sido posible evaluarla, ni asignarle una categoría.

\section{Macrolobium machaenioides Killip \& J.F. Macbr.}

Publicación: Field Mus. Nat. Hist., Bot. Ser. 13(3/ 1): 139-140. 1943.

Colección tipo: G. Klug 547

Hemarios: F, NY.

Nombre común: D esconocido.

Registro departamental: LO.

Regiones Ecológicas: BHA; 100 m.

SINAN PE: Sin registro.

Hemarios peruanos: Ninguno.

Observaciones: Especie arbórea descrita de una planta recolectada en 1929 de los alrededores de Iquitos, en la cuenca del Amazonas. Un ejemplar colombiano citado en TRO PICO S es adjudicado a esta especie, pero no pudo verificarse si esta identificación correcta. No ha sido posible evaluarla, ni asignarle una categoría.
233. Maraniona lavinii C.E. H ughes, Daza \& Reynel

NE

Publicación: Syst. Bot. 29(2): 371, 373374, f. 3. 2004.

Colección tipo: C.E. Hughes et al. 2209

Herbarios: FHO, K, MEXU, NY; MOLF,

USM.

Nombre común: D esconocido.

Registro departamental: AM, CA.

Regiones Ecológicas: BS; 1450-1600 m.

SINAN PE: Sin registro.

Herbarios peruanos: MO LF (holotipo citado+1), USM (isotipo citado+1).

Observaciones: Esta especie arbórea se conoce solamente de una estrecha franja altitudinal en el valle del Marañón, de colecciones recientes realizadas los últimos cinco años.

\section{Mimosa ctenodes Barneby}

Publicación: Mem. New York Bot. Gard. 65: 524. 1991.

Colección tipo: D.N. Smith 6170

Herbarios: MO, NY.

Nombre común: Desconocido.

Registro departamental: AM, CA.

Regiones Ecológicas: BS; $2500 \mathrm{~m}$.

SINANPE: Sin registro.

Henbarios penuanos: HAO (1).

Observaciones: Especie arbustiva conocida de poblaciones aparentemente dispersas en la cuenca del Marañón y la subcuenca del Matará. No ha sido posible evaluarla, ni asignarle una categoría.

235. Mimosa cuzcoana J.F. Macbr.

Publicación: Field Mus. Nat. Hist., Bot. Ser. 13(3/ 1): 88. 1943.

Colección tipo: C. Vargas C. 518

Hemarios: $F$.

Nombre común: D esconocido.

Registro departamental: CU.

Regiones Ecológicas: BMHM; 2000$2300 \mathrm{~m}$.

SINANPE: SHMP

Herbarios peruanos: Ninguno.

Observaciones: Especie arbustiva o bejuco descrita de una planta recolectada en la cuenca del Urubamba. O tras poblaciones provienen de la misma cuenca y del Marcapata. No ha sido posible evaluarla, ni asignarle una categoría.

\section{Mimosa incarum Barneby}

Publicación: Mem. New York Bot. Gard. 65: 576-577. 1991.

Colección tipo: A. Sagástegui A. \& S. Cabanillas 8447

Henbarios: NY; $\underline{\mathrm{HUT}}$.

Nombre común: Desconocido.

Registro departamental: CA, LL.

Regiones Ecológicas: BS; $1800-2600$ m.

SINANPE: Sin registro.

Herbarios penuanos: CPUN (1), HAO (1), HUT (isotipo citado). 
Observaciones: Arbusto conocido de la cuenca del Marañón. No ha sido posible evaluarlo, ni asignarle una categoría.

\section{Mimosa montana Kunth var. montana}

Publicación:

Colección tipo: A. Humboldt \& A.

Bonpland s.n.

Herbarios:

Nombre común: D esconocido.

Registro departamental: AN, PI.

Regiones Ecológicas: MA; 2380-2450 m.

SINAN PE: Sin registro.

Hemarios penuanos: HAO (1).

Observaciones: Este taxón fue considerado por Brako \& Zarucchi (1993) como un endemismo; sin embargo, no ha sido posible evaluarlo, ni asignarle una categoría.

\section{Mimosa montana Kunth var. sandemanii Barneby}

Publicación: Mem. New York Bot. Gard. 65: 89-90. 1991.

Colección tipo: C. Sandeman 4277

Herbarios:

Nombre común: D esconocido.

Registro departamental: AN, CA, PI.

Regiones Ecológicas: BS; $2100 \mathrm{~m}$.

SINANPE: Sin registro.

Herbarios penuanos: CPUN (1).

Observaciones: Este taxón fue considerado por Brako \& Zarucchi (1993) como un endemismo; sin embargo, no ha sido posible evaluarlo, ni asignarle una categoría.

\section{Mimosa pectinatipinna Burkart}

Publicación: Darwiniana 7(4): 523. 1947. Colección tipo: A. Humboldt \& A. Bonpland 3750

Herbarios: $B, P$.

Nombre común: D esconocido.

Registro departamental: AM, CA, PI.

Regiones Ecológicas: BS; 400-1000 m.

SINAN PE: Sin registro.

Herbarios penuanos: CPUN (1).

Observaciones: Especie arbustiva conocida de ambientes xéricos en las cuencas del Huancabamba y Marañón. No ha sido posible evaluarla, ni asignarle una categoría.

\section{Mimosa polycarpa Kunth var. polycarpa}

Publicación:

Colección tipo: A. Humboldt \& A.

Bonpland s.n.

Herbarios:

Nombre común: D esconocido.

Registro departamental: CA, LL.

Regiones Ecológicas: Sin datos; $2200 \mathrm{~m}$.

SINANPE: Sin registro.

Herbarios peruanos: Ninguno.

Observaciones: Taxón subarbustivo conocido del norte del país. No ha sido posible evaluarlo, ni asignarle una categoría.
241. Mimosa polycarpa Kunth var. redundans Barneby

Publicación: Mem. New York Bot. Gard. 65: 519. 1991.

Colección tipo: J. Sánchez 1682

Herbarios:

Nombre común: Tapa tapa.

Registro departamental: CA, JU, LL.

Regiones Ecológicas: MA; 2500-2650 m.

SINAN PE: Sin registro.

Hemarios peruanos: CPUN (1), HAO.

Observaciones: Taxón subarbustivo conocido del norte del país. No ha sido posible evaluarlo, ni asignarle una categoría.

\section{Ormosia peruviana Rudd}

EN, Blab(iii)

Publicación: Ann. Missouri Bot. Gard. 55(1): 79. 1968.

Colección tipo: F. Woytkowski 6964

Herbarios: MO, US.

Nombre común: Huayruro.

Registro departamental: AM, CA, SM.

Regiones Ecológicas: BMHM, BMHP; $650-2100 \mathrm{~m}$.

SINAN PE: Sin registro.

Herbanios penuanos: HAO (1).

Observaciones: Árbol descrito de una planta recolectada en la cuenca del Chamaya, en una zona ecotonal de bosque húmedo y seco. Estos ambientes montanos en el norte del Perú están sujetos a deforestación.

\section{Ormosia schunkei Rudd}

EN, Blab(iii)

Publicación: Phytologia 18(6): 337-338. 1969.

Colección tipo: J. Schunke V. 2998

Hemarios: F; MOLF.

Nombre común: Huairuro.

Registro departamental: $\mathrm{HU}, \mathrm{UC}$

Regiones Ecológicas: BHA; 200-400 m. SINANPE: Sin registro.

Herbarios peruanos: MOLF (isotipo).

Obsenvaciones: Especie arbórea conocida del centro oriente del país, de la cuenca del Pachitea. Esta especie fue descrita de una planta recolectada en los alrededores del Bosque Nacional de Iparía, hoy desactivado, por lo que el área no recibe protección y modificafa por extracción maderera.

\section{Paramachaenium schunkei Rudd}

\section{CR, Blab(iii)}

Publicación: Brittonia 33(3): 439, f. 1, 2A. 1981.

Colección tipo: J. Schunke V. 2595

Henbarios: F, MO, NY, SFV, US.

Nombre común: D esconocido.

Registro departamental: HU.

Regiones Ecológicas: Sin datos; altitud desconocida.

SINANPE: Sin registro.

Herbarios peruanos: Ninguno.

Observaciones: Esta especie arbórea se conoce solamente de la cuenca del Pachitea. El ejemplar tipo fue recolectado en 1968, del Bosque Nacional de Iparía, hoy desactivado. El área no recibe protección y hay incremento de la actividad maderera. 


\section{Parkinsonia penwianaC.E. Hughes, Daza \& Hawkins}

$$
\text { VU, Bla }
$$

Publicación: Kew Bull. 58: 467-472. 2003.

Colección tipo: C.E. Hughes 2213

Herbarios: FHO, K, MEXU, MO, NY; MOLF, USM!.

Nombre común: Goma de canaquil, pastilla. Registro departamental: AM.

Regiones Ecológicas: BS; 1060- 1140 m.

SINAN PE: Sin registro.

Herbarios peruanos: MOLF (holotipo+1); USM (isotipo+3).

Observaciones: Árbol conocido del bosque seco del Marañón y descrito de una colección de 2002. Aparentemente, su rango altitudinal no supera los $200 \mathrm{~m}$.

\section{Piptadenia killipii J.F. Macbr. var. killipii}

\author{
NT \\ Publicación: \\ Colección tipo: G. Klug 4333 \\ Herbarios: $\mathrm{F}, \mathrm{K}$. \\ Nombre común: D esconocido. \\ Registro departamental: JU, LO, PA, SM. \\ Regiones Ecológicas: BHA; 250-430 m. \\ SINANPE: RNT \\ Hembarios peruanos: Ninguno.
}

Observaciones: Liana descrita de una planta recolectada en 1936, de la cuenca del Huallaga. Esta especie es conocida de varias poblaciones dispersas en la Amazonía peruana, como en las cuencas del Pichis, Pozuzo y Tambopata. Amenazas a sus poblaciones están asociadas a la deforestación.

\section{Piptadenia weberbauen Harms}

\section{NT}

Publicación: Repert. Spec. Nov. Regni Veg. 18: 234. 1922.

Colección tipo: A. Weberbauer 7212

Herbarios: B, F.

Nombre común: D esconocido.

Registro departamental: AM, LL.

Regiones Ecológicas: BS; 520- $2000 \mathrm{~m}$.

SINANPE: Sin registro.

Hemarios peruanos: USM (2).

Observaciones: Árbol conocido del bosque seco del Marañón. Esta especie fue descrita de una planta recolectada en 1916. Una población adicional fue recolectada en 1964, en la misma cuenca.

\section{Pithecellobium mathewsii Benth.}

Publicación: London J. Bot. 3: 222. 1844. Colección tipo: A. Mathews s.n.

Herbarios:

Nombre común: D esconocido.

Registro departamental: SM.

Regiones Ecológicas: Sin datos; altitud desconocida.

SINANPE: Sin registro.

Hembarios peruanos: Ninguno.

Observaciones: Este taxón fue considerado por Brako \& Zarucchi (1993) como un endemismo; sin embargo, no ha sido posible evaluarlo, ni asignarle una categoría.
249. Platymiscium gracile Benth.

$$
\text { EN, Bla }
$$

Publicación: J. Linn. Soc., Bot. 4(Suppl.): 82- 83. 1860.

Colección tipo: R. Spruce 4228

Henbarios: BM, C, F, G, G H, K.

Nombre común: Desconocido.

Registro departamental: SM.

Regiones Ecológicas: BHA; 270-540 m.

SINANPE: Sin registro.

Herbarios penuanos: USM (1).

Observaciones: Árbol conocido solamente de la cuenca del Mayo. Bridgewater et al. (2003) listan esta especie en la flora de los bosques estacionalmente secos, pero aparentemente es un error; pues Klitgaard (2005) menciona recolectas realizadas en otra región ecológica. Esta especie se conoce de pocas poblaciones que habitan bosques intervenidos ribereños, aunque aparentemente no hay recolectas desde 1980. Klitgaard (2005) propuso esta especie en la categoría de En Peligro Crítico, pero se considera aquí En Peligro, ya que el hábitat de esta especie está poco herborizado.

\section{Poissonia orbicularis (Benth.) H auman}

Publicación: Bull. Misc. Inform. Kew 1925(6): 278. 1925.

Colección tipo: J. Pavón s.n.

Herbarios: K.

Nombre común: D esconocido.

Registro departamental: AP, AY, CU, HU, HV.

Regiones Ecológicas: MA; 2400-3200 m.

SINANPE: Sin registro.

Herbarios penuanos: CUZ?, USM?.

Observaciones: Estetaxón fue considerado por Brako \& Zarucchi (1993) como un endemismo; sin embargo, no ha sido posible evaluarlo, ni asignarle una categoría.

\section{Poissonia weberbauen (Harms) Lavin}

\section{EN, Bla}

Publicación: Syst. Bot. 28(2): 401. 2003. Colección tipo: A. Weberbauer 1567

Hemarios: B.

Nombre común: Desconocido.

Registro departamental: AR, IC.

Regiones Ecológicas: D ST; 285-300 m.

SINANPE: Sin registro.

Herbarios peruanos: CPUN (2).

Observaciones: Especie arbustiva, conocida solamente de poblaciones dispersas en las lomas de Arequipa. El ejemplar tipo fue recolectado en 1902 y desde entonces, las colecciones se extienden hasta fines de 1980.

\section{Senna aurantia (Ruiz \& Pav. ex G. Don) H.S. Irwin \& Barneby}

Publicación: Mem. New York Bot. Gard. 35: 354. 1982.

Colección tipo: H. Ruiz \& J. Pavón s.n.

Herbarios: MA

Nombre común: Desconocido.

Registro departamental: HU, JU, LI.

Regiones Ecológicas: MA; 2000-3100 m.

SINANPE: Sin registro.

Herbarios peruanos: Ninguno. 
Observaciones: Especie arbustiva conocida de varias localidades en ambas vertientes andinas, creciendo en matorrales dispersos. No ha sido posible evaluarla, ni asignarle una categoría.

\section{Senna birostris (Dombey ex J. Vogel) H.S. Irwin \& Barneby var. birostris}

Publicación:

Colección tipo: J. D ombey s.n.

Herbarios: P.

Nombre común: D esconocido.

Registro departamental: $\mathrm{AN}, \mathrm{HU}, \mathrm{JU}$, LL, LI, PA.

Regiones Ecológicas: MA; $2500 \mathrm{~m}$.

SINANPE: Sin registro.

Herbarios peruanos: Ninguno.

Observaciones: Arbusto descrito de una planta recolectada en el siglo XVIII, en la cuenca del Checras. Se conoce varias otras localidades dispersas, creciendo en matorrales. Este taxón fue considerado por Brako \& Zarucchi (1993) como un endemismo; sin embargo, no ha sido posible evaluarlo, ni asignarle una categoría.

\section{Senna birostris (Dombey ex J. Vogel) H.S. Irwin \& Barneby var. helveola (J.F. Macbr.) H.S. Irwin \& Barneby}

Publicación: Mem. New York Bot. Gard. 35:343. 1982.

Colección tipo: J.F. Macbride \& \& W. Featherstone 1183

Herbarios:

Nombre común: D esconocido.

Registro departamental: AN, AR, CA, LI, PA.

Regiones Ecológicas: MA, PSH; 2600$3900 \mathrm{~m}$.

SINANPE: PNH

Herbarios penuanos: CPUN (5).

Observaciones: Arbusto localmente frecuente, descrito de una planta recolectada en 1923, en la cuenca alta del Huertas. No ha sido posible evaluarlo, ni asignarle una categoría.

\section{Senna cushina (J.F. Macbr.) H.S. Irwin \& Barneby}

Publicación: Mem. New York Bot. Gard. 35: 475. 1982.

Colección tipo: J.F. Macbride \& \& W. Featherstone 4825

Herbarios: $F$.

Nombre común: D esconocido.

Registro departamental: AM, HU, SM.

Regiones Ecológicas: MA; altitud desconocida.

SINANPE: Sin registro.

Herbarios peruanos: Ninguno.

Observaciones: Esta especie perenne fue descrita de una planta recolectada en la cuenca del Huertas, un tributario del Huallaga. No ha sido posible evaluarla, ni asignarle una categoría.
256. Senna haughtii (J.F. Macbr.) H.S. Irwin \& Barneby

Publicación: Mem. New York Bot. Gard. 35: 587. 1982.

Colección tipo: 0 . Haught F10

Herbarios: F, GH.

Nombre común: D esconocido.

Registro departamental: PI.

Regiones Ecológicas: DCT; altitud desconocida.

SINANPE: Sin registro.

Herbarios peruanos: Ninguno.

Observaciones: Planta arbustiva conocida de dos ejemplares recolectados en los 1930 de la costa norte del país. No ha sido posible evaluarla, ni asignarle una categoría.

\section{Senna lonetensis (Killip \& J.F. Macbr. ex Killip) H.S. Irwin \& Barneby}

Publicación: Mem. New York Bot. Gard. 35: 146. 1982.

Colección tipo: J.M. Schunke 206

Herbarios:

Nombre común: D esconocido.

Registro departamental: AM, LO, MD, SM.

Regiones Ecológicas: BHA; 130- 750 m.

SINAN PE: Sin registro.

Herbarios peruanos: Ninguno.

Observaciones: Especie arbórea conocida de varias localidades dispersas en la Amazonía peruana. no ha sido posible evaluarla, ni asignarle una categoría.

\section{Senna malaspinae H.S. Irwin \& Barneby}

Publicación: Mem. New York Bot. Gard. 35:311- 312. 1982.

Colección tipo: F.W. Pennell 14424

Herbarios: NY, US.

Nombre común: D esconocido.

Registro departamental: LI.

Regiones Ecológicas: MA; 3100-3200 m.

SINANPE: Sin registro.

Hemarios peruanos: Ninguno.

Observaciones: Arbusto conocido de la cuenca del Chillón. Esta especie habita laderas mésicas. No ha sido posible evaluarlo, ni asignarle una categoría.

\section{Senna monilifera H.S. Irwin \& Barneby}

$$
\text { EN, B1a }
$$

Publicación: Brittonia 44(2): 226-227. 1992. Colección tipo: S. Llatas Q. 2834

Hembarios: F, NY.

Nombre común: D esconocido.

Registro departamental: CA.

Regiones Ecológicas: BMHM; 2100$2300 \mathrm{~m}$.

SINAN PE: Sin registro.

Herbarios penuanos: CPUN (1).

Observaciones: Esta especie perenne se conoce solamente de dos localidades en Cajamarca, ubicadas al sureste de los límites del Parque Nacional Cutervo. Amenazas potenciales a sus poblaciones probablemente estén asociadas a deforestación y cambios asociados del hábitat. 
260. Senna pendula (H umb. \& Bonpl. ex Willd.) H.S. Irwin \& Barneby var. scandens (Benth.) H.S. Irwin \& Barneby

Publicación: Mem. New York Bot. Gard. 35: 395. 1982.

Colección tipo: R. Spruce 3925

Herbarios: K.

Nombre común: D esconocido.

Registro departamental: SM.

Regiones Ecológicas: $\mathrm{BHA}$; altitud desconocida.

SINANPE: Sin registro.

Herbarios peruanos: Ninguno.

Observaciones: Planta perenne conocida de la colección tipo, una planta recolectada en el siglo XIX. No ha sido posible evaluarla, ni asignarle una categoría.

\section{Senna praeterita H.S. Irwin \& Barneby}

Publicación: Mem. New York Bot. Gard. 35: 333-334. 1982.

Colección tipo: A. Mathews 3276

Herbarios:

Nombre común: D esconocido.

Registro departamental: AM.

Regiones Ecológicas: Sin datos; altitud desconocida.

SINANPE: Sin registro.

Herbarios peruanos: Ninguno.

Observaciones: Este taxón fue considerado por Brako \& Zarucchi (1993) como un endemismo; sin embargo, no ha sido posible evaluarlo, ni asignarle una categoría.

\section{Senna uncata H.S. Irwin \& Barneby}

Publicación: Mem. New York Bot. Gard. 35: 200, 202, f. 19. 1982.

Colección tipo: E. Ancuash A. 289

Herbarios: MO, NY.

Nombre común: D esconocido.

Registro departamental: AM.

Regiones Ecológicas: BHA; 200-300 m.

SINAN PE: Sin registro.

Herbarios peruanos: Ninguno.

Observaciones: Este taxón fue considerado por Brako \& Zarucchi (1993) como un endemismo; sin embargo, no ha sido posible evaluarlo, ni asignarle una categoría.

\section{Senna vargasii (Schery) H.S. Irwin \& Barneby}

Publicación: Mem. New York Bot. Gard. 35: 373. 1982.

Colección tipo: C. Vargas C. 985

Hemarios: $\mathrm{MO}$

Nombre común: D esconocido.

Registro departamental: CU.

Regiones Ecológicas: BMHM; altitud desconocida.

SINANPE: SHMP

Herbarios peruanos: Ninguno.

Observaciones: Este taxón fue considerado por Brako \& Zarucchi (1993) como un endemismo; sin embargo, no ha sido posible evaluarlo, ni asignarle una categoría.
264. Senna versicolor var. heterosperma H.S. Irwin \& Barneby

Publicación: Mem. New York Bot. Gard. 35: 309-310. 1982.

Colección tipo: P.C. Hutchison \& J.K.

Wright 5306

Herbarios: NY, UC.

Nombre común: D esconocido.

Registro departamental: CA.

Regiones Ecológicas: MA; 2900 m.

SINANPE: Sin registro.

Herbarios penuanos: CPUN (1).

Observaciones: Esta especie es conocida de la cuenca del Marañón. A parentemente es rara en las localidades de las que se conoce. No ha sido posible evaluarla, ni asignarle una categoría.

\section{Swartzia calva R.S. Cowan}

Publicación: Proc. Biol. Soc. Wash. 86(39): 454-455. 1973.

Colección tipo: J.M. Schunke 2509

Herbarios:

Nombre común: Desconocido.

Registro departamental: AM, LO, SM.

Regiones Ecológicas: Sin datos; altitud desconocida.

SINANPE: Sin registro.

Herbarios peruanos: Ninguno.

Observaciones: Estetaxón fue considerado por Brako \& Zarucchi (1993) como un endemismo; sin embargo, no ha sido posible evaluarlo, ni asignarle una categoría.

\section{Swartzia gracilis Pipoly \& Rudas}

Publicación: Novon 4(2): 167-168, f. 2. 1994.

Colección tipo: R. Vásquez et al. 17951

Herbarios: MO, US.

Nombre común: Desconocido.

Registro departamental: LO.

Regiones Ecológicas: BHA; $150 \mathrm{~m}$.

SINAN PE: Sin registro.

Herbarios peruanos: Ninguno.

Observaciones: Este taxón arbóreo fue descrito posterior a Brako \& Zarucchi (1993); no ha sido posible evaluanlo, ni asignarle una categoná.

\section{Swartzia huallagae D.R. Simpson}

Publicación: Phytologia 30(5): 313-315. 1975.

Colección tipo: J. Schunke V. 4490

Herbarios: $F, G$, US.

Nombre común: D esconocido.

Registro departamental: LO, SM.

Regiones Ecológicas: $\mathrm{BMHP}, \mathrm{BHA}$;

altitud desconocida.

SINANPE: Sin registro.

Hembarios peruanos: Ninguno.

Observaciones: Árbol descrito de una planta recolectada en 1970, de la cuenca del Huallaga. Poblaciones adicionales son conocidas de subcuencas del Amazonas. Este taxón fue considerado por Brako \& Zarucchi (1993) como un endemismo; sin embargo, no ha sido posible evaluarlo, ni asignarle una categoría. 
268. Tachigali peruviana (Dwyer) Zarucchi \& H erend.

Publicación: Monogr. Syst. Bot. Missouri Bot. Gard. 45: 1254. 1993.

Colección tipo: L. Williams 5701

Herbarios: $F$.

Nombre común: Sacha espintana.

Registro departamental: JU, SM.

Regiones Ecológicas: BMHP; $785 \mathrm{~m}$.

SINANPE: Sin registro.

Herbarios peruanos: MOLF (1).

Observaciones: Especie arbórea descrita de una planta recolectada en los 1920, de la cuenca del Mayo. No ha sido posible evaluarla, ni asignarle una categoría.

\section{Tachigali uleana (Harms) Zarucchi \& Herend.}

Publicación: Monogr. Syst. Bot. Missouri Bot. Gard. 45: 1254. 1993.

Colección tipo: E.H.G. Ule 6450

Herbarios: F, K, MO, US.

Nombre común: D esconocido.

Registro departamental: SM.

Regiones Ecológicas: BHA; 350 m.

SINAN PE: Sin registro.

Herbarios peruanos: Ninguno.

Observaciones: Especie arbórea descrita de una planta recolectada en lacuencadel Mayo. No hasido posibleevaluarla, ni asignarleunacategoní.

\section{Vicia penuviana Vilchez}

Publicación: Darwiniana 17: 501. 1972.

Colección tipo: 0 . Velarde 6595

Herbarios: MOL.

Nombre común: D esconocido.

Registro departamental: JU.

Regiones Ecológicas: MA; altitud desconocida.

SINANPE: Sin registro.

H erbarios peruanos: MOL (holotipo citado).

Observaciones: Hierba conocida solamente del centro del país. No ha sido posible evaluarla, ni asignarle una categoría.

\section{Weberbauerella brongnartioides Ulbr.}

\section{EN, B 1ab(iii)}

Publicación: Bot. Jahrb. Syst. 37(5): 551553, f. 1. 1906.

Colección tipo: A. Weberbauer 1513

Hemarios: $B$.

Nombre común: D esconocido.

Registro departamental: AR.

Regiones Ecológicas: D ST; $20-300 \mathrm{~m}$.

SINANPE: Sin registro.

Herbarios peruanos: CPUN (1), MOL

(1), USM?

Observaciones: Esta es la especie tipo de este género endémico al Perú. Fue descrita de una planta subarbustiva recolectada a inicios del siglo XX, de una de las lomas de los alrededores de Mollendo. Fue nuevamente a ser recolectada en 1986 durante un evento El Niño. Amenazas a sus poblaciones estarían asociadas a modificación de su hábitat.

\section{Weberbauerella raimondiana Ferreyra}

$$
\text { EN, Blab(iii) }
$$

Publicación: Publ. Mus. Hist. Nat. «Javier Prado», Ser. B, Bot. 3: 2-4, f. s.n. 1951.

Colección tipo: R. Ferreyra 6498

Henbarios: US; USM.

Nombre común: D esconocido.

Registro departamental: AR, IC.

Regiones Ecológicas: D ST; $300-400$ m.

SINANPE: Sin registro.

Herbarios peruanos: USM (isotipo citado+1).

Observaciones: Subarbusto conocido de dos poblaciones disyuntas en la costa sur del país. Esta especie habita ambientes influenciados por la neblina costera. Fue descrito de una planta recolectada en ambientes de lomas. Posteriormente, ha sido hallada de sitios arenosos y aislados (León et al. 1997). Amenazas a sus poblaciones están asociadas a modificación de su hábitat. La biología de esta especie requiere ser estudiada.

\section{Zygia guinetii L. Rico}

\section{DD}

Publicación: Kew Bull. 46(3): 500-501, f. 2 A-F. 1991.

Colección tipo: R. Vásquez et al. 5373

Herbarios: K, MO ; AMAZ!.

Nombre común: D esconocido.

Registro departamental: LO.

Regiones Ecológicas: BHA; $130 \mathrm{~m}$.

SINANPE: RNAM

Herbarios penuanos: AMAZ (isotipo).

Observaciones: Arbusto trepador conocido de las cuencas del Yavarí y del Nanay. Esta especie habita bosques inundables. El ejemplar tipo proviene de la Reserva Nacional Allpahuayo-Mishana. Es posible que esta especie esté representada en la flora de Brasil.

\section{Zygia megistocarpa (C. Barbosa) L. Rico}

\section{LC}

Publicación: Kew Bull. 46(3): 502. 1991. Colección tipo: E. Ancuash 1211 Hemarios: MO.

Nombre común: D esconocido.

Registro departamental: AM.

Regiones Ecológicas: BHA; $180-600$ m.

SINANPE: Sin registro.

Henbarios peruanos: Ninguno.

Observaciones: Especie arbustiva 0 arbórea conocida de las cuencas del Santiago y del Cenepa, en el área que hoy se reconoce como Zona Reservada Santiago-Comaina. 
Mapa del Perú indicando las abreviaturas de los departamentos

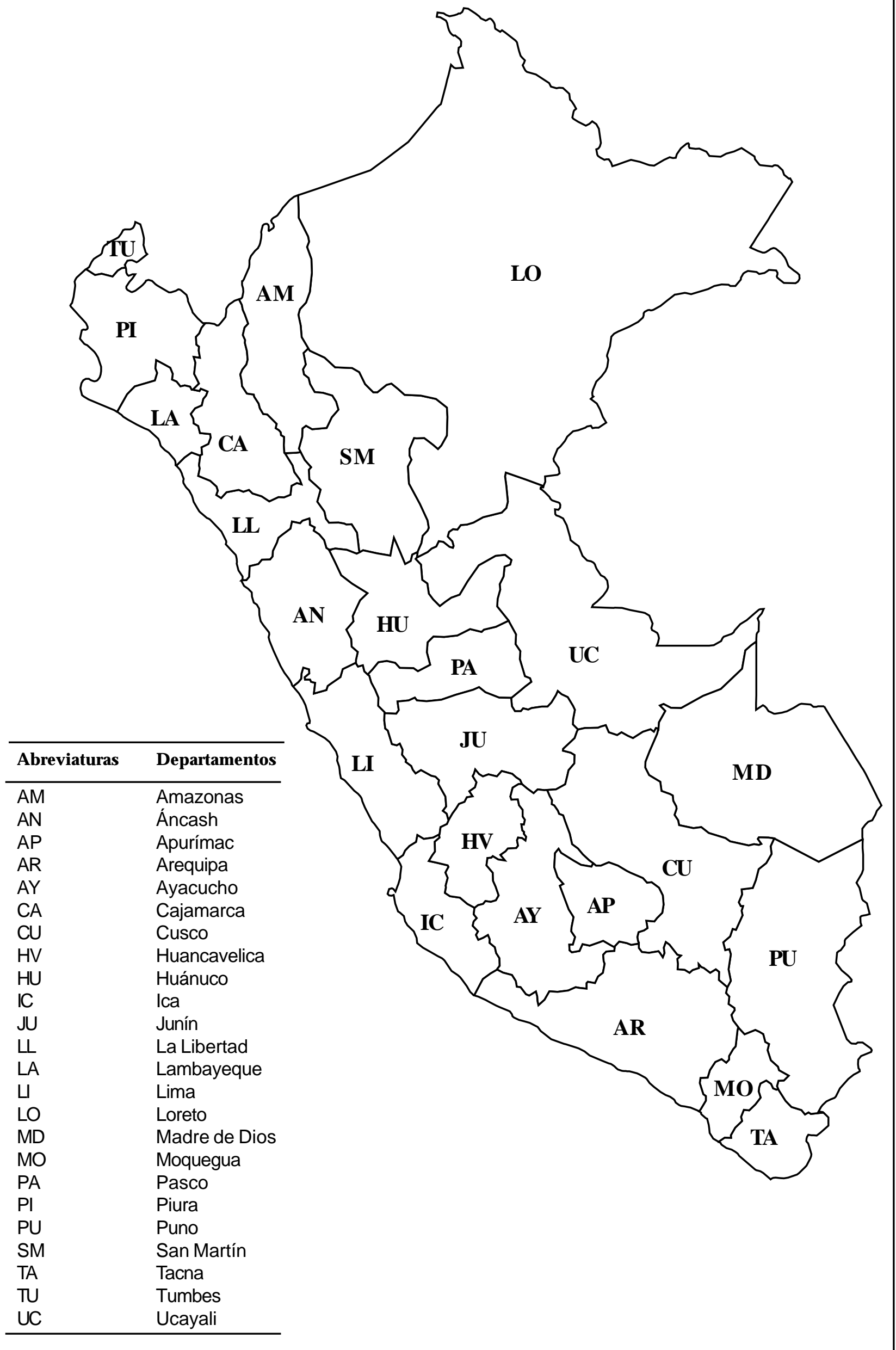

